\title{
Análisis y tipología de brechas viarias dentro del palimpsesto urbano de València
}

\author{
Analysis and typology of street fissures \\ within the urban palimpsest of València (Spain) \\ Joan Carles Membrado Tena \\ joan.membrado@uv.es \\ Ghaleb Fansa Saleh \\ ghaleb.fansa@uv.es \\ Jorge Hermosilla Pla \\ jorge.hermosilla@uv.es \\ Departamento de Geografía \\ Unidad de investigación ESTEPA. Estudios del Territorio, Paisaje y Patrimonio \\ Universitat de València (España)
}

\section{Resumen}

El palimpsesto urbano es el resultado de la superposición y yuxtaposición diacrónica de una serie de modelos de desarrollo urbano que han determinado, en mayor o menor medida, la trama viaria actual. Resultado de esta dinámica, la trama urbana de muchas ciudades presenta una serie de brechas viarias singulares - por sus formas sinuosas, transversales u oblicuas- que dan carácter e identidad al paisaje urbano. En este artículo se analizan -mediante SIG y revisión bibliográfica - las brechas viarias del palimpsesto urbano, tomando como paradigma el plano de la ciudad de València. Se lleva a cabo también una original categorización de las brechas viarias de acuerdo a una taxonomía derivada de su estructura y funcionamiento. Siguiendo la 
metodología explicada, esta tipología de brechas viarias es extrapolable a cualquier otro caso de estudio que disponga de material cartográfico e historiográfico adecuado sobre su secular desarrollo urbano.

Palabras clave: Brecha viaria; palimpsesto; tipología; SIG; València.

\begin{abstract}
The urban palimpsest is the result of the diachronic juxtaposition and superposition of a series of development models that have determined, more or less, the current street network. As a result of this dynamics, the urban fabric of many cities shows a series of singular street fissures - due to their sinuous, transverse or oblique shapes - that give character and identity to the urban landscape. This paper analyzes - through a GIS and a literature review -the street fissures of the urban palimpsest, taking as a paradigm the city plan of València (Spain). A cataloging of singular street fissures is also carried out according to a taxonomy derived from their structure and functioning. Following the explained methodology, this typology of Street fissures can be extrapolated to any other case study that has adequate maps and literature on its secular urban development.
\end{abstract}

Key words: Street fissure; palimpsest; typology; GIS; València.

\title{
1 Introducción
}

Desde la geografía urbana y otras disciplinas afines se ha abordado el tema del palimpsesto, término científico difundido a partir de 1845 tras la publicación por Thomas De Quincey del ensayo titulado The palimpsest of the human brain. La palabra palimpsesto deriva del latín

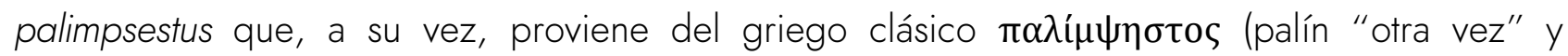
mpsēstos "rascado, grabado"). Hasta mediados del siglo XIX este término definía cualquier manuscrito donde se conservasen huellas de una escritura anterior que no había podido ser completamente borrada por otras posteriores y que era posible rastrear, analizar y reconstruir. Tras la publicación de De Quincey, el concepto del palimpsesto, en sentido figurado, se ha empleado en arquitectura, geografía y otras ciencias para referirse a formas que cohabitan entre sí pero que a la vez se entrelazan e interrumpen (Dillon, 2005, p. 245).

El palimpsesto urbano describe, mediante sus incoherentes trazados, una estructura histórica y económica anterior que no ha podido ser totalmente disimulada por otras posteriores, y que deja 
huellas y redundancias, obsolescencias e irracionalidades (Crang, 1996; Oliveira, 2016; Fouseki et al., 2019).

Corboz (2004) plantea el reto que supone para los diseñadores urbanos planificar las próximas capas del palimpsesto urbano de manera que se adapten a las necesidades futuras sin que se ejerza demasiada violencia sobre lo que hubo en el pasado. Khirfan (2010, p. 315), destaca la significación simbólica del patrimonio urbano de las ciudades históricas respecto a los diseños innovadores de las formas contemporáneas.

Vâlceanu et al. (2014, p. 24) defienden que el reconocimiento de las características del palimpsesto urbano actual es fundamental para diseñar desarrollos urbanos futuros, no solo con el fin de preservar el patrimonio, sino también para aumentar la calidad de vida, que está ligada, entre otros factores, a la preservación de la identidad cultural. En este sentido, el palimpsesto urbano conecta con conceptos como el de paisaje-memoria (que explica la formación de identidades territoriales) y paisaje-indicador (que evalúa la calidad del paisaje) (Tesser, 2000, p. 24-25; Nogué, 2007, p. 374).

Bartolini (2014, p. 524) matiza y acota el término palimpsesto al considerar que la yuxtaposición urbana de elementos materiales, espaciales y temporales debe ser definida bajo el concepto de brecha (brecciation) mientras que el término palimpsesto debe restringirse a la superposición cronológica de huellas del pasado que permanecen ocultas.

Desde el punto de vista de la percepción, Huyssen (2003, p. 7) vincula el palimpsesto a la comprensión de los espacios urbanos como espacios sentidos que dan forma a imaginarios colectivos, y pone de ejemplo Berlín, tras la reunificación, cuyo centro reconstruido proporciona un ejemplo clave para el funcionamiento de tal imaginario. Marvell \& Simm (2016, p. 125) definen los paisajes urbanos como palimpsestos o capas superpuestas de geografía, historia, cultura y política que pueden descifrarse para comprender mejor el sentido de cada lugar.

El objetivo principal y aportación más novedosa de este artículo, más allá de la interpretación tangible o perceptiva del palimpsesto, se fundamenta en la creación de una metodología específica de estudio evolutivo del paisaje urbano, basada en la categorización de las anomalías o brechas viarias que se reconocen sobre el palimpsesto urbano. Dicha categorización, que se lleva a cabo a partir del análisis del paisaje urbano de la ciudad de València, es extrapolable a cualquier ámbito urbano si se aplica la metodología expuesta y se dispone de los materiales requeridos. 
Un segundo objetivo radica en que este análisis y taxonomía de brechas viarias sirva no solo transferencia de conocimientos, sino también como instrumento de aplicación al entorno de la planificación urbanística en ciudades donde la conservación de la trama y, en particular de las brechas viarias, sea parte de las agendas políticas municipales.

El tercer objetivo consiste en una descripción sintética de los principales procesos seculares de urbanización para ver bajo qué diferentes contextos históricos y económicos se han generado las brechas viarias. Este último objetivo se desarrolla en el apartado 2, donde se repasan cronológicamente conceptos y modelos urbanos, ilustrados con ejemplos significativos, con el fin de alcanzar una mayor profundidad en el análisis, comprensión y categorización de las brechas viarias, que es el objetivo principal del artículo.

\section{Brechas viarias y trama urbana}

El palimpsesto urbano, manifestado a menudo a través de brechas viarias, es fruto de un proceso de continua construcción, renovación, destrucción y reconstrucción desde sus momentos iniciales. Por ejemplo, en el Próximo Oriente hay ciudades pobladas durante más de seis milenios sobre el mismo solar fundacional: Alepo y Damasco se disputan el mérito de ser las ciudades habitadas más antiguas del mundo, habiendo sido destruidas y reconstruidas varias veces a lo largo de su historia (Shackley, 1998). Varios barrios de Alepo y Damasco se encuentran, de hecho, actualmente (2020) en ruinas, a la espera de ser reconstruidos una vez finalizada la guerra de Siria. La marca de la estructura urbana previa al conflicto seguirá siendo determinante, probablemente, durante la futura reconstrucción de dichos barrios. Así lo ha sido, normalmente, en las reconstrucción, reforma y expansión de las ciudades.

La continuidad entre las estructuras urbanas viarias actuales y las de la Antigüedad se manifiesta en ciudades como Nápoles, en cuyo centro histórico aún son discernibles los trazados, heredados de la colonización griega del s. VI a. C., de los Decumanus inferior, mayor y superior (Regina \& Giglio, 2016). Una parte de la actual trama viaria de Segovia sigue estando determinada hoy por su acueducto romano (s. II), así como una parte de la de Zaragoza lo está por sus murallas (s. I-III), y una parte de las de Nimes, Arles, Verona y Pula por sus respectivos anfiteatros (s. I); lo mismo se puede decir de Split, cuyo centro es ocupado por el Palacio de Diocleciano (s. IV); de Bosra (Siria) y Amman (Jordania) con sus respectivos teatros (s. II); y de elDjem (Túnez) con su anfiteatro (s. III). La propia Roma, salpicada de monumentos clásicos como el Coliseo y el Foro, es paradigma de esta influencia secular sobre la trama viaria. Salónica, arrasada por un incendio en 1917, posee una trama planificada y moderna que integró algunos 
monumentos romanos, bizantinos y otomanos, que hoy marcan discontinuidades sobre el callejero (Mazower, 2007, p. 324). Estambul es una ciudad básicamente otomana que, sin embargo, integra monumentos bizantinos como Santa Sofía y las murallas.

En la Europa Atlántica la huella de la Antigüedad es irrelevante, pero no la de un pasado más reciente. Tras el incendio de Londres de 1666 su núcleo histórico o City fue reconstruido en piedra y ladrillo, manteniendo y ensanchando el trazo medieval de sus calles (Hebbert, 2018). Más el este, el centro histórico de Varsovia (s.XIII-XX), completamente destruido en 1944, fue rehecho durante el periodo comunista y declarado en 1980 Patrimonio de la UNESCO por su fidedigna reconstrucción edilicia y viaria (Jankowski, 1990).

Se observa, en general, que la arquitectura residencial es la que más se renueva, mientras los trazados urbanos persisten más, y los espacios y edificios públicos son los más duraderos. Así sucede en València, donde casi todos los edificios residenciales de su casco antiguo datan del siglo XIX y XX, pero conviven con palacios e iglesias góticas (s. XIV-XV) sobre una trama urbana en gran parte medieval. $\bigcirc$ en Beijing, donde gran parte de la trama urbana y edilicia (Hutong) ha sido demolida y el nuevo trazado, de calles más anchas y edificios más altos, ha integrado la histórica Ciudad Prohibida (Meyer, 2010). O también en la moderna Ciudad de México, cuyo Zócalo o plaza mayor preserva el trazado viario y edilicio de época colonial (Wildner, 2018).

En los actuales palimpsestos urbanos es variada la tipología y el origen de las brechas urbanas que se pueden encontrar. En los siguientes epígrafes se muestra cuál ha sido el germen de los principales tipos de brecha, que puede estar relacionado con un camino agrícola tradicional, un canal, una barrera (natural o artificial), un trazado ferroviario o una reforma urbana planificada.

\subsection{Caminos y tramas históricas}

Muchas ciudades han preservado los ejes viarios de la Antigüedad, por mucho que sus viviendas pueden haber sido sustituidas varias veces (Capel, 2002, p. 80). Estos antiguos ejes viarios suelen yuxtaponerse en forma de brecha sobre trazados posteriores planificados (Tabla 1).

En Palermo, la calle del Cassaro (del árabe Qasr, "fortaleza, alcázar") se corresponde con un camino fenicio (VII-VI a. C.) que dividía la ciudad en dos (Francesio et al., 2012, p. 94). En Roma, la actual calle del Corso se corresponde con la histórica Via Flaminia (s. III a.C.), que llegaba hasta Rímini (Calci, 2012, p. 5). La calle de Saint-Denis de París fue trazada por los romanos, habiendo sobrevivido su trazo sinuoso a la regularización haussmanniana (Feroci \& Vibrac, 2018). 
Por lo que respecta a las tramas viarias medievales, han sobrevivido en mayor o menor medida en la Córdoba Omeya, la Sevilla Almohade, la Granada Nazarí, el casco medieval o Ciutat Vella de Palma, Barcelona o València, la Venecia ducal o la Roma papal. Bastante más modificada fue la trama viaria medieval de Catania que, tras el terremoto de 1693, fue reconstruida y convertida en paradigma de urbanismo barroco ortogonal (Francesio et al., 2012, p. 211). O Lisboa, cuyo barrio de Baixa fue reedificado y regularizado tras el terremoto de 1755 (Lima \& Neto, 2017). París, cuyo casco medieval y trama viaria fue en gran parte alterada por el Plan Haussmann de 1852-1870 (Paccoud, 2016). Los centros históricos de Nápoles (Alisio, 1980) y Florencia (Orefice, 1992) también experimentaron sendos Risanamenti o reestructuraciones urbanas, durante el siglo XIX. O el Puerto Viejo de Marsella, cuyo tramo norte fue demolido en 1943 por las tropas nazis con la colaboración de las autoridades de Vichy (Bonillo \& Borruey, 1992).

\subsection{Caminos del agua}

Dada su función comercial, menestral, industrial o agrícola, los caminos acuáticos han condicionado notablemente el trazado viario en las fases iniciales del desarrollo de las ciudades, y han determinado algunas tramas urbanas históricas, dando lugar a brechas (trazados irregulares), condicionados por el recorrido sinuoso de los cursos de agua (Tabla 1).

El origen de grandes ciudades europeas está condicionado por cursos fluviales como pasa en Sevilla con el Guadalquivir, Zaragoza con el Ebro, Londres y el Támesis, Roma y el Tíber, Colonia y el Rin, o Budapest y el Danubio. El origen de París se halla en una isla fluvial (île de la Cité) del río Sena, y el de Nueva York en la isla de Manhattan, enmarcada por los ríos Hudson, Harlem y East River. Lyon se emplaza en una península fluvial (la Presqu'île) en la confluencia del Saona y el Ródano; y Coblenza (latín: Confluentia) en la del Rin y el Mosela. El origen de Ginebra se encuentra en una colina protegida por el lago Leman, los ríos Ródano y Arve, y una ciénaga.

Tal vez la ciudad cuyo desarrollo urbano está más condicionado por el agua es Venecia: compuesta por 118 islas lagunares unidas por 435 puentes, fue fundada en el siglo VII en este emplazamiento estratégico por la población tardorromana del entorno, que huía de los invasores bárbaros (Cho, 211). También sobre una laguna, la actual Ciudad de México fue fundada por los mexicas con el nombre de México-Tenochtitlán en un islote cercano a la ribera occidental del lago de Texcoco; dicho islote fue ampliado artificialmente, pero tras la conquista castellana la trama urbana mexica fue reemplazada por otra desvinculada del lago, que fue artificialmente desecado (Legorreta, 2006, p. 25). Suzhou, junto al río Yangtsé, es un modelo urbano único 
donde las vías fluviales se planificaron bajo un patrón ortogonal (Shengfang, 1986). Los canales de Ámsterdam, Brujas, San Petersburgo o Milán fueron diseñados con fines defensivos, comerciales o de gestión hídrica (desecación de pantanos y abastecimiento urbano).

En las ciudades hortícolas mediterráneas, los canales y acequias han influido en tramas viarias como las de Murcia, donde la céntrica calle de la Acequia (hoy llamada Acisclo Díaz, Maestro Alonso y Santa Clara) coincidía con el recorrido de la Acequia Mayor de la Aljufía (Navarro y Jiménez, 2012). Por su parte, la Séquia de Rovella y el Rec Comtal introducían agua en el interior de las ciudades de València y Barcelona, respectivamente, para dar servicio a curtidurías y alfarerías, limpiar cloacas y regar huertos urbanos. Parte del trazado de ambas acequias se ha fosilizado sobre la trama viaria de València (Sanchis, 2002, p. 103) y de Barcelona (Capel, 1999).

En ciudades mediterráneas cabe señalar que algunos cursos fluviales intermitentes fueron incorporados a la trama urbana como calles: las ramblas de Barcelona y Alacant, el antiguo cauce del Torrent de la Riera (actual paseo del Born) de Palma, y la Rambla de Predicadors (actual plaza de Tetuán y avenida de Navarro Reverter) en València (Carmona, 1997, p. 90).

\subsection{Barreras naturales}

La expansión urbana, en ocasiones, encuentra ciertos límites y barreras naturales que tienen gran transcendencia en la configuración urbana (Capel, 2002, p. 84-85). Las barreras de tipo natural se deben a la orografía: cerros, pantanos, desniveles hidrográficos o presencia del mar. Las brechas orográficas se adapta la forma del relieve y por ello suelen presentar formas irregulares (Tabla 1).

La influencia de la orografía es notable en el Madrid de los Austrias (y luego en el borbónico), cuya trama urbana se desarrolló únicamente hacia el este, ya que al oeste se hallaba el río Manzanares, con una caída de unos 50 m entre su lecho y el emplazamiento original madrileño. La urbanización al sur de la Barcelona medieval se vio dificultada históricamente debido a la montaña de Montjuïc, que solo empezó a urbanizarse con la exposición de 1929. Tanto Roma como Estambul son famosas por sus siete colinas, que condicionaron históricamente sus caóticos trazados viarios.

En València, el exiguo caudal del río Turia supuso una barrera urbana -más psicológica que real- que no se superó hasta la Exposición Regional de 1909. Posteriormente, en 1986, este mismo río fue desviado y convertido en el mayor jardín urbano longitudinal de España, con una forma sinuosa adaptada al cauce. La zona noroeste tanto de Sevilla (al otro lado del 
Guadalquivir), como de Zaragoza (al otro lado del Ebro), históricamente inundables, solo se edificaron decididamente a raíz de la celebración de las Expos de 1992 y 2008, respectivamente.

El mar supone una ventaja comercial y defensiva para las ciudades que se emplazan a su vera, pero también un obstáculo insalvable para el desarrollo urbano, por mucho que modernamente algunas ciudades, como Algeciras y València, hayan ganado terreno al mar para ampliar su frente litoral y portuario. Muchas urbes comerciales se desarrollaron en la Antigüedad y el Medievo sobre las aguas calmas del Mediterráneo: Málaga, Alacant, Palma, Barcelona, Marsella, Génova, Nápoles, Palermo o Salónica. En el caso de Dubrovnik, dos secciones (la oriental y la meridional) de las cuatro de su muralla son resguardadas por el mar Adriático; y en Estambul tres secciones de las cuatro que posee su recinto histórico están protegidas por el mar: el Cuerno de Oro, al norte; el estrecho del Bósforo, al este; y el mar de Mármara, al sur.

\subsection{Murallas}

Las barreras urbanas pueden ser también de tipo artificial, como los recintos amurallados, que fueron progresivamente demolidos a lo largo del siglo XIX por obsoletos y por obstaculizar la expansión moderna. El derribo de las murallas supuso la liberación de un espacio que, en forma de trinchera entre el casco antiguo y el ensanche burgués, fue ocupado por una serie de rondas que -en forma de brecha viaria- marcan una discontinuidad entre la densa trama medieval y los holgados ensanches (Tabla 1).

Tanto en València como, sobre todo, en Barcelona las murallas frenaron la expansión física de la ciudad hasta mediados del siglo XIX, y obligaron a densificar la trama urbana y elevar la edificatoria para albergar una población intramuros creciente. En ambas ciudades la discontinuidad entre la trama medieval y su Eixample está bien marcada en la actualidad por una serie de rondas. En Zaragoza el espacio viario que ocupaba la antigua muralla romana es conocido como el Coso (latín: cursus, "camino (de ronda)"). Viena es conocida por su Ring, un boulevard de $5 \mathrm{~km}$ de longitud y unos 50 metros de ancho que ocupa el espacio liberado tras el derribo de las murallas. Los Grands Boulevards parisinos se construyeron a lo largo del siglo XVIII sobre el espacio que se liberó, en la margen derecha del Sena, tras la demolición de la muralla de Carlos V y Luis XIII de Francia. En Madrid, el derribo de la cerca de Felipe IV creó una brecha que dibuja un polígono cuyos tramos más reconocibles lo configuran las rondas de Segovia, Toledo, Valencia y Atocha. 


\subsection{Revolución industrial y caminos de hierro}

La revolución industrial provocó a lo largo del siglo XIX profundos cambios en las ciudades, que experimentaron un rápido crecimiento demográfico. Dicho incremento no se correspondió con una planificación urbana adecuada, ya que predominó el crecimiento puramente especulativo de las ciudades, que quedaron divididas en barrios fabriles e insalubres para la clase trabajadora, y áreas residenciales de la burguesía con amplias avenidas y espacios verdes (Gomis \& Turón, 2015, p. 45).

Más allá de las contradicciones sociales que generó, la revolución industrial fomentó extraordinariamente el desarrollo de los caminos de hierro, que permitían transportar mercancías y personas a velocidades notables (Álvarez et al., 2016). Por un lado, el ferrocarril mejoró la accesibilidad, pero, por otro, obstaculizó de manera notable el desarrollo urbano y generó segregación social al otro lado de las vías. La locución inglesa the wrong side of the tracks describía originalmente un barrio conflictivo por encontrarse en el lado segregado de las vías (aunque hoy se refiere a cualquier barrio conflictivo). Así pues, el ferrocarril, una vez demolidas las murallas, se convirtió en la principal barrera artificial para el crecimiento urbano.

Aunque a lo largo de los siglos XX y XXI muchos caminos de hierro han acabado siendo soterrados o desmantelados, la incidencia de los mismos sobre la trama viaria continúa siendo notable: normalmente propician la creación de una brecha cubierta (que cubre el túnel por donde circulan las vías) o fósil (que ocupa el espacio liberado por el desmantelamiento de las vías) (Tabla 1). A menudo, la disposición de estas brechas viarias es transversal al trazado de las calles adyacentes, lo cual resulta muy conveniente, dado que la transversalidad viaria facilita y acorta las distancias, especialmente cuando predomina una trama ortogonal.

Aparte de la Diagonal y la Meridiana (diseñadas como vías rápidas de penetración y confluencia en la céntrica plaza de Les Glòries), la única vía importante que no sigue un trazado ortogonal en el Eixample de Barcelona es la avenida de Roma, por donde circula -soterrado actualmenteel tramo inicial del ferrocarril entre la estación de Sants y la plaza de Catalunya. El ferrocarril de circunvalación de Madrid, que conectaba las estaciones de Atocha y Príncipe Pío, tras su soterramiento dejó una notable brecha urbana en el Distrito de Arganzuela. Algunas de las más importantes avenidas (ver Figura 10) de València fueron en el pasado tendidos ferroviarios.

\subsection{Reformas interiores}

A finales del siglo XIX, ya sin murallas y en pleno auge del ferrocarril, los urbanistas comenzaron a reflexionar sobre la expansión y crecimiento de las ciudades. Es el momento de desarrollo de 
los ensanches y, a la vez, se aboga por la reforma interior de los cascos antiguos para conectarlos a dichos ensanches (Capel, 2002, p. 374). Las reformas interiores acabaron generando un tipo de brecha inversa ( $y$, por lo tanto, regular) que se superpuso al trazado medieval espontáneo (Tabla 1).

El gran precedente de reforma interior fue el Plan Haussmann de París (1853-1870): un vasto programa de obras públicas, dirigido por el barón Haussmann, que implicó la demolición de barrios medievales hacinados, y la construcción de avenidas, parques, plazas o nuevo alcantarillado. El Plan Haussmann se vio interrumpido por la guerra franco-prusiana (1870), pero luego se retomó y perduró hasta 1927, de forma que la actual trama urbana parisina es, en gran parte, resultado de este ambicioso plan de reforma interior (De Moncan \& Heurteux, 2002).

En Roma se llevaron a cabo algunas reformas interiores de menor calado que la parisina, como la apertura, superpuesta al antiguo trazado medieval, del corso Vittorio Emanuele (1886) y de la vía Cavour (1910). Quizá la actuación más conocida sea la demolición de la medieval Via Alessandrina, Ilamada así en honor del papa valenciano Alejandro VI, para crear la famosa Via della Conciliazione, inaugurada en 1936 por Mussolini para conectar mejor la ciudad con el Vaticano (Boira, 2020, p. 136).

La haussmannización de las grandes ciudades españolas fue remarcable desde mitad del XIX a mediados del XX, sobre todo tras la promulgación de la Ley de Saneamiento y Mejora Interior de Grandes Poblaciones, de 1895 (García-Doménech et al, 2012, p. 205). En Barcelona se abrió la Via Laietana (1908-1913) y se reformaron las calles adyacentes a esta, conectando así el nuevo ensanche con el viejo puerto a través de una vía rápida que se superponía al trazado medieval (Figura 1). En pleno Madrid de los Austrias se abrió la Gran Vía (1910-1930) y se reformaron las calles adyacentes a esta, enlazando la calle de Alcalá, al este, con la calle de la Princesa, al noroeste (Figura 2).

Superpuesta a la trama medieval se creó en 1903 la calle de la Pau en València, que unía el este del casco antiguo con la céntrica plaza de la Reina (Figura 6). En Zaragoza se abrió la calle de Alfonso I en 1865, destripando el casco antiguo, para comunicar la basílica del Pilar con el Coso. En Málaga se inauguró en 1891 la calle de Larios, que enlazaba el frente marítimo con la céntrica plaza de la Constitución. En Sevilla la avenida de la Constitución, que une la Puerta de Jerez con la céntrica Plaza Nueva, fue concluida en 1911. Ya a mediados del siglo XX se abrió en Murcia la Gran Vía, que partía en dos su casco antiguo. Lo mismo se intentó en València a mediados del siglo XX con la avenida del Oest para comunicar el sur y el norte del casco 
antiguo, pero solo se completó un tercio del proyecto debido a la falta de financiación tras la devastadora riada de 1957 (Figura 6).

Figura 1. Barcelona: principales reformas interiores (s. XX). Via Laietana y calles adyacentes

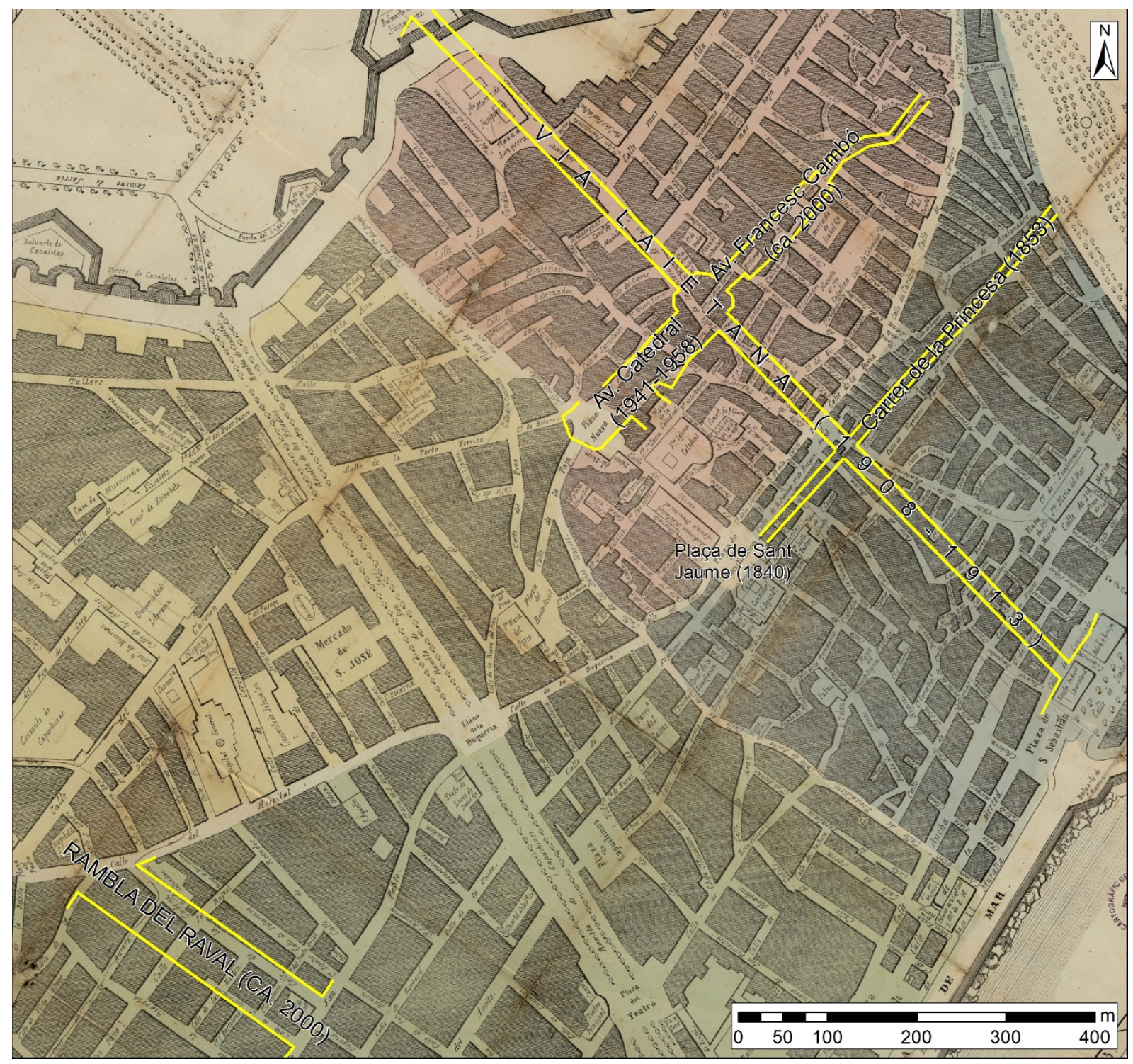

Fuente: elaboración propia a partir de ICGC (2020) y CNIG (2020) 
Figura 2. Madrid: principales reformas interiores ( $1^{\mathrm{a}}$ mitad s. $\mathrm{xx}$ ):

\section{Gran Vía y calles adyacentes}

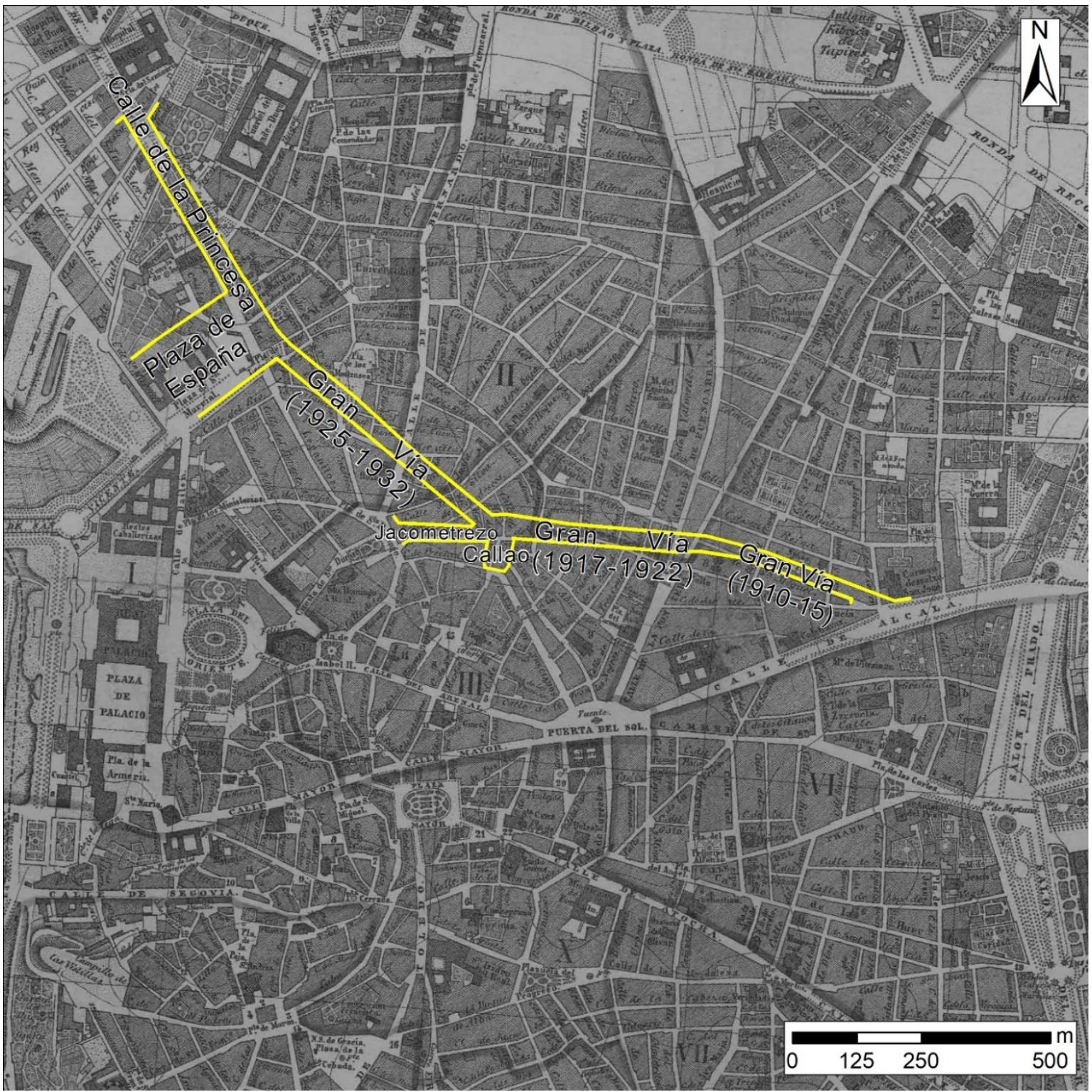

Fuente: elaboración propia a partir de BVM (2020) y CNIG (2020)

\subsection{Ensanches ortogonales extramuros}

La expansión urbana tras el derribo de las murallas en el siglo XIX se llevó a cabo habitualmente siguiendo una trama ortogonal planificada, donde las calles se cruzan en ángulo recto. Dada su simplicidad y racionalidad en la ordenación espacial, este tipo de plano, también llamado en damero, en cuadricula o en parrilla, ha sido el preferido por los planificadores urbanos desde la Antigüedad y hasta el siglo XX (Capel, 2002, p. 157).

Hacia el 2600 a. C., la ciudad harappa de Mohenjo-Daro (Valle del Indo) fue construida a partir de un plano ortogonal. Otras culturas a lo largo del planeta, como la egipcia (Amarna, s. XIV a. 
C.), babilónica (s. VII a. C.), griega (s. VIII-V a. C.), teotihuacana (s. I d. C.), china (Chang'an o Xian, s. VII-X), inca (Cuzco, s. XIII) o mexica (Tenochtitlán, s. XIV), crearon ciudades ex Novo de diseño ortogonal. Frente al desarrollo urbano espontáneo, el plano en damero implica una planificación consciente e impone un orden conceptual racional que trasciende el tiempo y el espacio y proclama el control y el poder de la autoridad central (Grant, 2001).

Roma y Atenas crecieron orgánicamente condicionadas por una orografía que en el pasado había sido propicia para su defensa. Por el contrario, usaron la cuadrícula para diseñar sus colonias. Gracias a la maestría de Hipodamo de Mileto (s. V a. C.), los griegos perfeccionaron el plano ortogonal (también llamado hipodámico) y lo aplicaron en la propia Mileto (paradigma de este tipo de plano), y también en otras ciudades como las fundadas sobre el territorio conquistado por Alejandro Magno y colonizado por sus generales (como la ptolemaica Alejandría durante el siglo III a. C.) (Higgins, 2009).

Siguiendo el paradigma hipodámico, los romanos fundaron muchas de sus colonias basándose en el cardo (orientación N-S) y el decumanus (E-O). Entre estas cabe citar Valentia (València, 138 a. C.), cuya planta ortogonal fue alterada debido al abandono altomedieval y la superposición de la traza espontánea árabe. O Augusta Taurinorum (Turín), donde la cuadrícula romana aún es hoy perceptible en el llamado Quadrilatero Romano (Semi, 2004). Durante la Edad Media cristiana son notables en Languedoc, Gascuña y Aquitania las bastidas de trama cuadriculada. Este tipo de ciudades fortificadas también se fundan al sur de los Pirineos, en villas valencianas como Vilareal (Rosselló, 2018). Según Bielza de Ory (2002), el modelo ortogonal de bastida fue exportado a colonias castellanas de América, como Santo Domingo o la propia Ciudad de México. El mismo modelo ortogonal fue desarrollado por los ingleses en fundaciones norteamericanas como Filadelfia o Nueva York o por los estadounidenses (tras su independencia) en Washington D. C. o Chicago.

La discontinuidad de la trama urbana histórica respecto a los ensanches ortogonales es remarcable: las rondas de la muralla marcan normalmente una brecha viaria -a manera de trinchera- entre ambos tipos de tejido (Tabla 1). Solo algunas calles principales del casco antiguo se integran - a manera de brecha- en el tejido cuadriculado del ensanche (Fuencarral, Hortaleza-Almagro y Alcalá en el ensanche madrileño; Saint-Denis en la trama haussmanniana parisina; Broadway en la cuadrícula neoyorkina; Quart y Russafa en el ensanche de València; o Ribes en el de Barcelona). 
No todos los planos ortogonales son idénticos ni en la morfología ni en la disposición espacial: algunos exhiben chaflanes que crean una pequeña plaza en cada cruce (Barcelona, València); otros presentan manzanas rectangulares y no cuadradas (Nueva York, Filadelfia); otros se extienden sin solución de continuidad desde el mismo centro histórico hacia la periferia (Turín, Nápoles); y, en cambio, otros presentan una clara discontinuidad entre una trama histórica, más o menos irregular, y un ensanche ortogonal planificado (Barcelona, València, Madrid).

\subsection{Brechas y tramas contemporáneas}

Hubo que esperar al siglo XX para que, gracias a urbanistas como los firmantes de la Carta de Atenas (1933), se diseñara un nuevo modelo funcionalista de ciudad basado en modelos racionales de igualdad y desarrollo social (Mumford, 2002).

La transición entre los ensanches burgueses de la primera mitad el XX y la arquitectura racionalista de la segunda mitad suele ser brusca: una calle principal suele marcar -a manera de brecha costura- la discontinuidad entre ambos modelos de desarrollo (Tabla 1). Solo algunas calles principales del ensanche burgués o del barrio proletario de preguerra se prolongan a través del nuevo tejido funcionalista de la segunda mitad del s. XX.

Durante el siglo XXI la planificación racionalista continúa siendo el paradigma de expansión en la periferia urbana. Así lo fue durante el boom inmobiliario español (1997-2007) y así sigue siendo tras la reactivación económica posterior al estallido de la burbuja especulativa.

Habrá que observar si la grave crisis sociosanitaria y económica derivada de la COVID-19 nos llevará hacia un modelo de ciudad más sostenible e igualitario desde el punto de vista social y medioambiental o si, por el contrario, se perpetuarán los mismos patrones urbanos imperantes.

A la vez, en la periferia distante de las ciudades se ha ido desarrollando con el cambio de milenio otro paradigma, mucho más agresivo y depredador del territorio: el urbanismo expansivo o urban sprawl, caracterizado por la vivienda unifamiliar y la baja densidad edificatoria (Membrado-Tena, 2015, p. 264). Los detractores del urbanismo expansivo consideran que este modelo consume cantidades insostenibles de energía, agua y suelo agrícola y forestal, y, además, destruye la vida comunitaria y segrega a las personas en función de su nivel de renta (Gillham, 2002, p. 72; Mantecón et al., 2016, p. 69). Esta segregación deriva de la deficiente o inexistente accesibilidad peatonal entre la ciudad compacta y la suburbana, ya que a menudo una vía rápida de comunicación - a manera de brecha barrera (Tabla 1) - se interpone entre ambos tejidos, y subordina la movilidad de los residentes suburbanos al uso del vehículo privado. 
Tras examinar los principales factores y modelos urbanos determinantes de las brechas viarias, se va a proceder al análisis del palimpsesto de València, paradigma de ciudad mediterránea con más de dos milenios de historia cuya complejidad tipológica viaria se debe a un secular proceso de yuxtaposición o superposición de modelos urbanos.

\section{Métodos y materiales}

Para llevar a cabo el análisis de la compleja morfología viaria de València se parte de una lectura cartográfica del palimpsesto. Este examen permite detectar sobre el mapa brechas discordantes sobre la estructura urbana, que responden a marcas del pasado que el tiempo no ha podido eliminar y que hoy resultan llamativas y de difícil interpretación dentro del contexto global de la trama viaria.

La observación de los mapas es, por lo tanto, la que despierta la curiosidad en primer lugar e induce al análisis de las irregularidades detectadas sobre la trama viaria. La propia cartografía -su tratamiento y manipulación - es también el instrumento principal en el que se basa nuestro análisis viario: la superposición y georreferenciación de capas diacrónicas permite analizar y averiguar el origen de las brechas del palimpsesto que distorsionan el orden aparente de la trama urbana. Por lo tanto, partiendo de un enfoque inductivo (observación cartográfica), se pasa a aplicar un método deductivo (manipulación cartográfica) para satisfacer nuestra curiosidad.

El material cartográfico proviene principalmente de los planos del siglo XIX y primera mitad del XX extraídos de Llopis \& Perdigón (2016), que han sido georreferenciados y superpuestos a mapas actuales como el BTN25 (CNIG, 2020), y a ortofotografías de 1956-57 (ICV, 2020a) y de 2019 (ICV, 2020c). Toda la cartografía ha sido tratada mediante un Sistema de Información Geográfica y se complementa con una amplia revisión bibliográfica.

\section{Resultados}

La lectura y análisis cartográfico del palimpsesto viario de València permite establecer una tipología de brechas viarias en función de su origen y forma. Este apartado se ha dividido en epígrafes correspondientes a cada una de las tipologías que se ha categorizado en este artículo y que se resumen en la Tabla 1. 


\subsection{Brecha directa}

Dentro de este epígrafe cabe referirse a los caminos agrícolas que fueron creados previamente a la expansión de la ciudad y que condicionaron su posterior crecimiento viario. Los caminos rurales marcan el crecimiento de la ciudad en las primeras fases -las menos planificadas- del desarrollo urbano.

Figura 3. Red radial de caminos rurales desde València hacia su periferia inmediata (c. 1900)

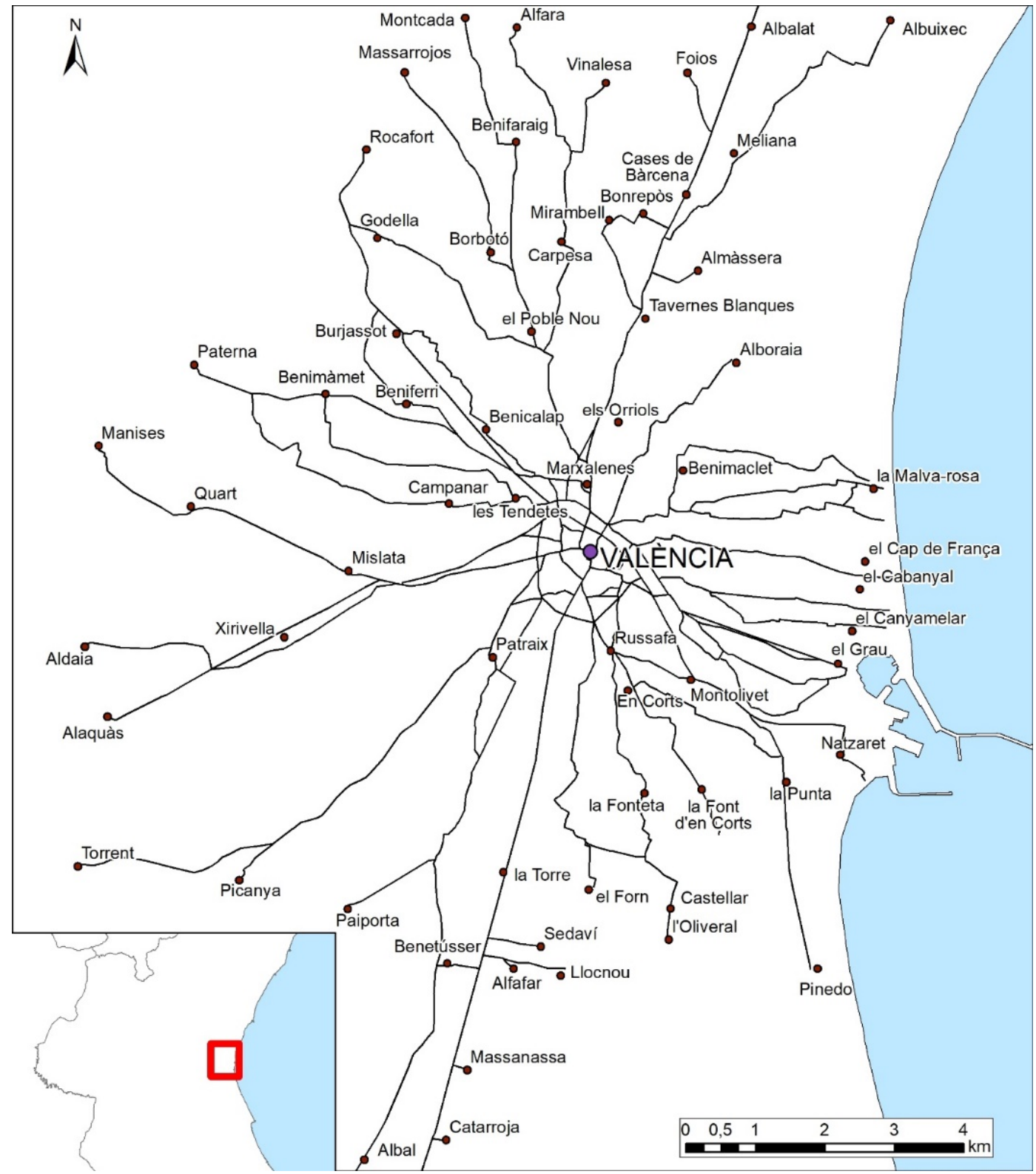

Fuente: elaboración propia a partir de Llopis \& Perdigón (2010, p. 46), ICV (2020a) y Esquilache (2015, p. 357) 
En la Figura 3 se aprecia la trama radial de caminos propia de la huerta de València antes del desarrollo urbano metropolitano de la segunda mitad el siglo XX (Hermosilla-Pla e Iranzo, 2014, p. 60). Esta trama viaria se irradia en todas direcciones desde la Ciutat Vella (casco antiguo) de València hacia sus pueblos huertanos. Algunos de estos caminos corresponden todavía en la actualidad a calles principales de la trama urbana, si bien cuanto más se alejan de la Ciutat Vella, más probable es que se interrumpan y desaparezcan bajo áreas urbanas planificadas, más allá de las cuales es posible que vuelvan a aparecer.

En la Figura 4 se observa un perímetro de unos $5 \mathrm{~km}$ alrededor del centro y se marca en negro los trazados viarios que, a manera de brecha directa, han perdurado al yuxtaponerse a las nuevas tramas regulares. Algunos han conservado su nombre histórico en el callejero viario, referido al topónimo que era destino final del mismo: Quart, Russafa, Alboraia, Sagunt, Montcada, Burjassot o Grau/Port. En rojo se marcan los trazados viarios que han sido engullidos por las nuevas tramas planificadas. Parte de los caminos desaparecidos reaparecen al cruzar los núcleos urbanos tradicionales (el Grau, el Cabanyal, la Malva-rosa, Benimaclet, Alboraia, Benicalap, Campanar, Patraix, Russafa, la Fonteta, en Corts, Natzaret) o en áreas agrícolas más allá del límite urbano.

Por lo que respecta a los caminos del agua, la incidencia de las acequias en la trama viaria de València es notable en Ciutat Vella, pero se diluye extramuros, ya que cuando se desarrollan los ensanches del XIX y XX la posibilidad técnica de cubrir las acequias permite que las calles pueden superponerse a las mismas.

En la trama viaria de la Ciutat Vella (Figura 5) es remarcable el papel de la acequia de Rovella, que regaba su entorno inmediato e introducía agua en su interior para dar servicio a curtidurías y alfarerías, limpiar cloacas, y regar huertos urbanos. Creada en época andalusí (ca. siglo IX), las brechas directas dejadas por esta acequia y sus ramales son remarcables. Justo antes de entrar en la Ciutat Vella, las aguas de Rovella se desviaban por un ramal hacia el norte y otro hacia el sur, siguiendo el foso nuevo (Vall Nou) de la muralla del siglo XIV. Mientras tanto, el canal principal de Rovella penetraba por la actual calle de la Corona (antigua calle dels Tints o "tintorerías", a las que abastecía), que conserva el mismo trazado que la acequia original andalusí (Figura 5). Luego giraba hacia el sur por la calle de Sant Miquel y la plaza del Tossal, donde conectaba con el foso viejo (Vall Vell) de la medina islámica del siglo XI. Las marcas (brechas directas) más notables de la acequia alrededor de la medina están, en su brazo norte, en la calle de la Mare Vella ("[acequia] madre vieja") y la de Comèdies y, en su brazo sur, en la 
plaza del mercado, Davallada ("bajada") de Sant Francesc (hoy del Ajuntament) y calle de les Barques. La acequia principal de Rovella (Figura 5), tras recibir las aguas de la acequia Rajosa, proveniente de la calle de Quart, seguía hacia el sur describiendo un trazado sinuoso (brecha directa) para mantener la cota (calles del Moro Zeid, Santa Teresa y Peu de la Creu) (Figura 12). Luego la acequia seguía hacia el sur por la calle dels Adreçadors y hacia el sureste para abandonar la Ciutat Vella por la cota más baja y llegar hasta el núcleo de Russafa (Martí, 2002, p. 66).

Figura 4. Red de caminos históricos de la ciudad de València (c. 1900) sobre el plano actual

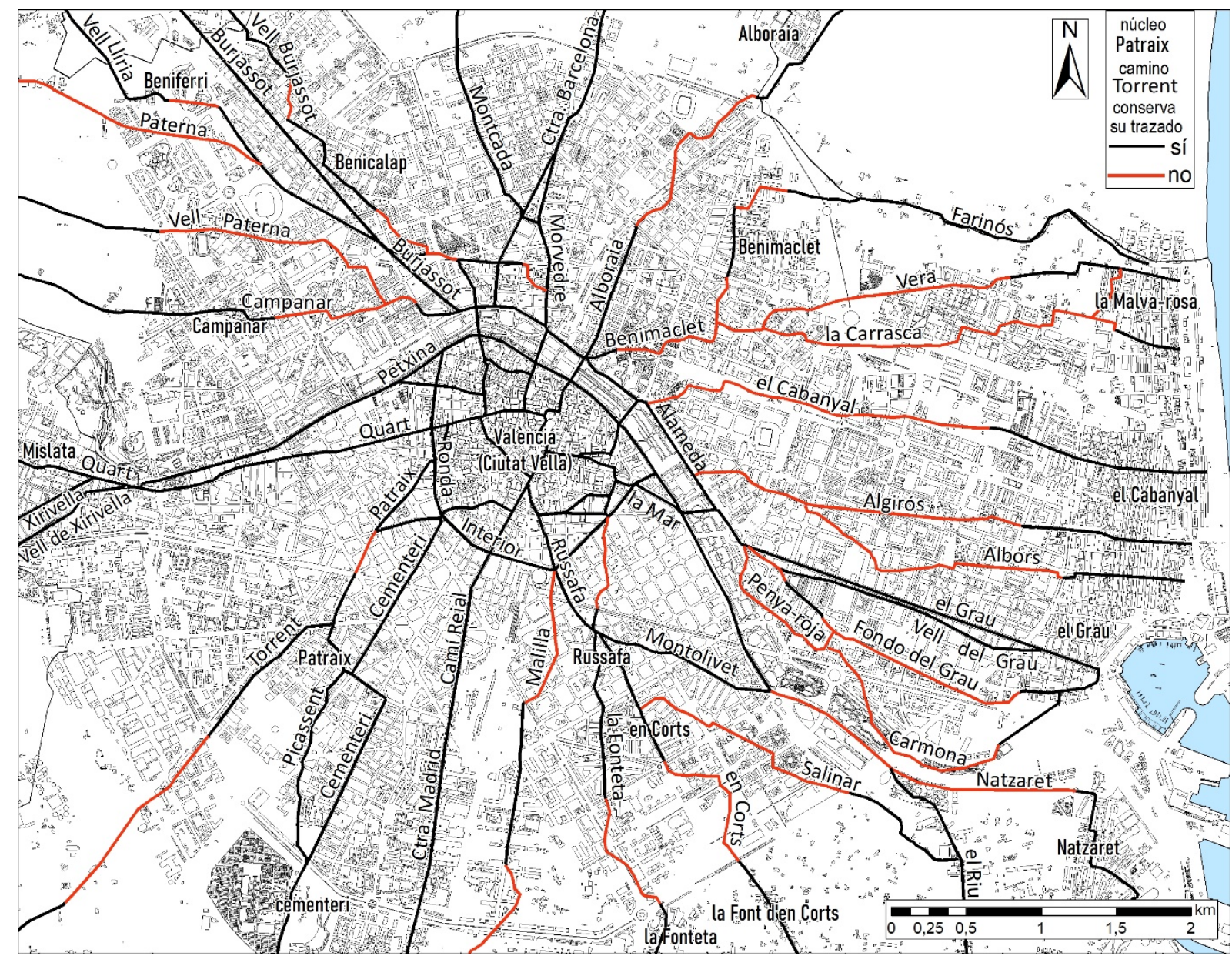

Fuente: elaboración propia a partir de Llopis \& Perdigón (2010, p. 46), CNIG (2020), ICV (2020a) y Esquilache $(2015$, p. 357)

En el distrito de Poblats Marítims (Figura 5) de València las acequias también juegan un papel primordial en la trama viaria, ya que su trazado, a manera de brecha directa, coincide con cada una de las calles principales que, en sentido O-E, separa los barrios históricos: el Grau, el Canyamelar, el Cabanyal, el Cap de França y la Malva-rosa. 
Figura 5. Red de acequias de València (s. XIX) en Ciutat Vella y Poblats Marítims

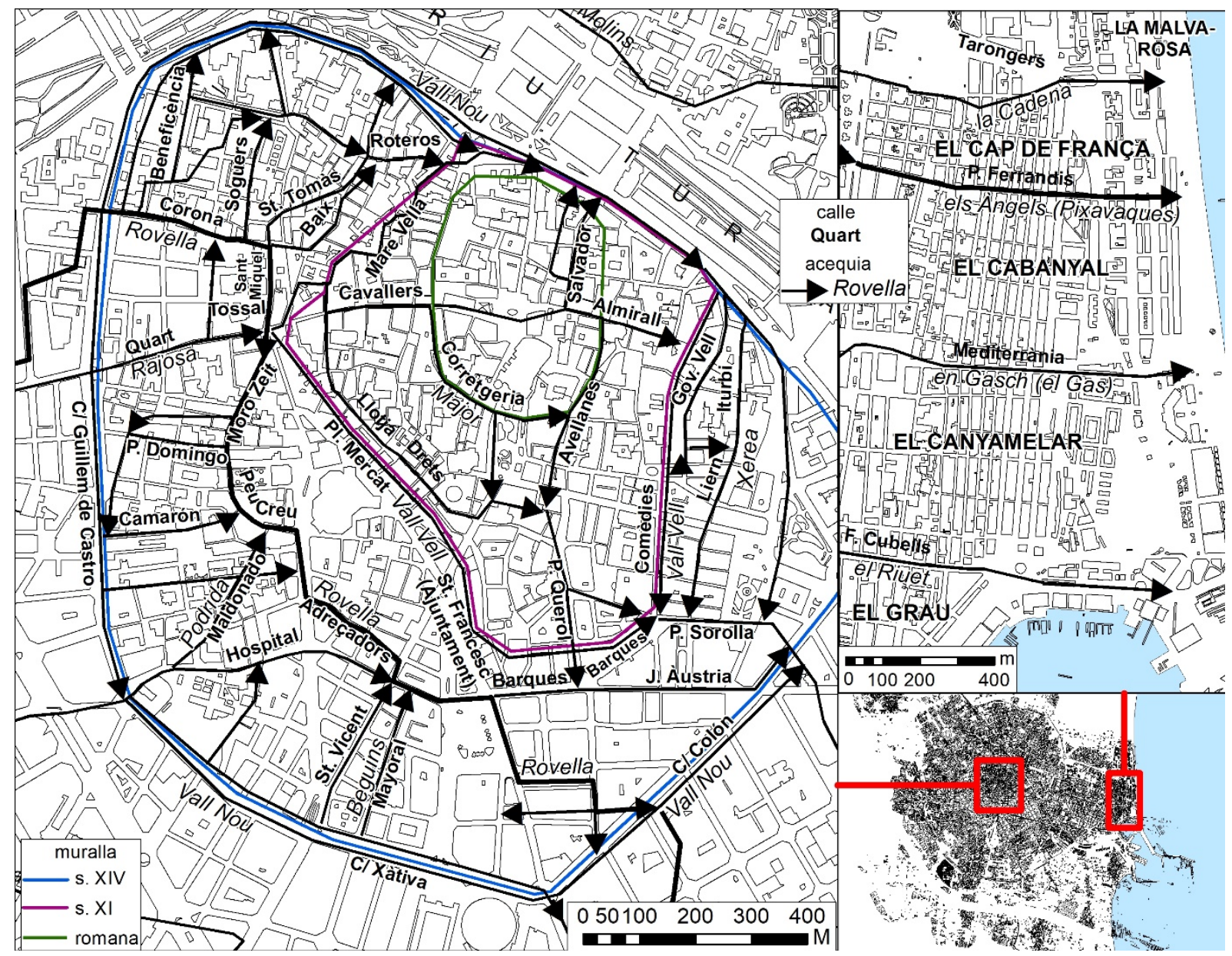

Fuente: elaboración propia a partir de Sanchis (2002, p. 94) y Aguilar \& Serra (2017)

\subsection{Brecha inversa}

Las brechas inversas derivan a menudo de los sventramenti o destripamientos urbanos (s. XIX y XX) que tuvieron lugar en los degradados centros históricos de las ciudades con el fin de esponjarlos y sanearlos y, a la vez, conectarlos a los nuevos ensanches. En la ciudad de València cabe señalar el proyecto de reforma interior que pretendía dividir la Ciutat Vella mediante un eje de este a oeste y otro de norte a sur. Ninguno de los dos fue completado. En 1903 se abrió la calle de la Pau, una brecha inversa entre el este de la Ciutat Vella y la céntrica plaza de la Reina, y que se preveía que llegaría al oeste del casco antiguo (Boira, 2001, p. 164) (Figura 6). A mediados del siglo XX se abrió la avenida del Oest, otra brecha inversa que proyectaba unir la Ciutat Vella de sur a norte y que solo se implementó en el tercio meridional de su recorrido, ya que el proyecto se quedó sin presupuesto tras los estragos causados por la riada de 1957. La apertura de una gran avenida como la del Oest generó procesos de segregación, al crear una barrera física y psicológica entre un barrio burgués (Sant Francesc, al este) y otro degradado 
(Velluters, al oeste) (Figura 6). Otras reformas interiores generadoras de brechas inversas menores fueron las de las calles Pascual i Genís, Correus, Llòria y Barques (1907) o Poeta Querol (1963) (Teixidor, 2001) (Figura 6).

Figura 6. València: principales reformas interiores (s. XIX-XX)

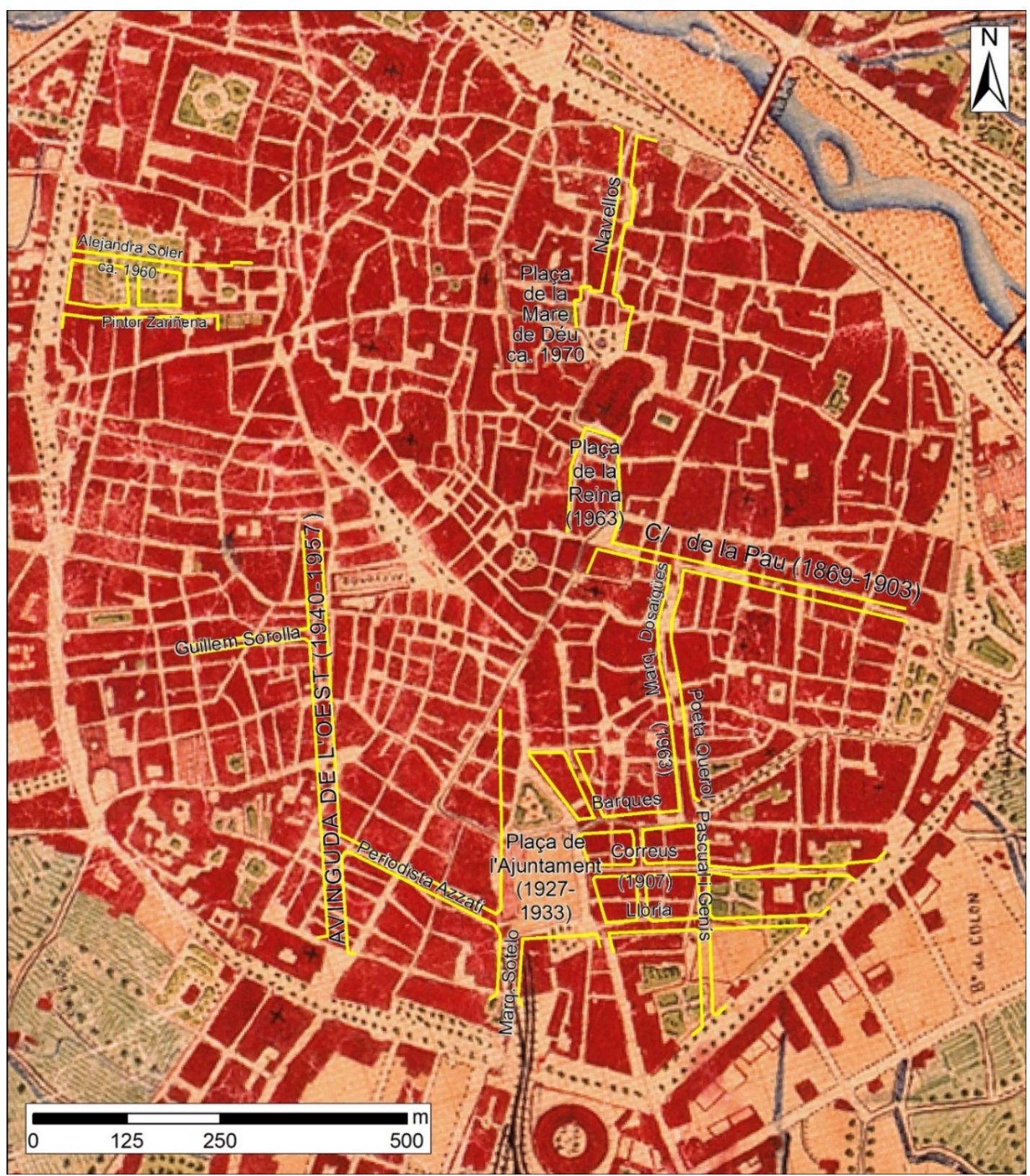

Fuente: elaboración propia a partir de Plano de Valencia y sus alrededores 1882 (Llopis \& Perdigón, 2010, p. 46) y BTN25 (CNIG, 2020)

Los proyectos de prolongación de la avenida del Oest y de la calle de la Pau se abandonaron durante la segunda mitad de siglo XX, al cambiar el paradigma desarrollista y funcionalista por otro conservacionista. No corrió la misma suerte el histórico barrio marítimo valenciano del Cabanyal-Canyamelar, ya que en 1998 el ayuntamiento aprobó el Plan Especial de Protección y 
Reforma Interior (PEPRI), que proyectaba la demolición de una parte del mismo para prolongar la funcionalista avenida de Blasco Ibáñez hasta la misma playa (Figura 7). La contestación ciudadana contra el PEPRI fue notable, pero no evitó la demolición de decenas de viviendas y la pérdida de miles de habitantes, dado el intencionado proceso de degradación al que fue sometido este sector del Cabanyal-Canyamelar por parte del ayuntamiento (Hervás, 2017; Boira, 2019). No fue hasta 2015 cuando la nueva corporación municipal derogó el plan de prolongación, evitó la previsible brecha inversa viaria que se hubiese generado, y empezó la rehabilitación de este barrio único por su arquitectura modernista popular y su trama urbana ortogonal (Figura 7).

Figura 7. PEPRI del Cabanyal-Canyamelar anulado (propuesta de Prolongación Avda. Blasco Ibáñez)

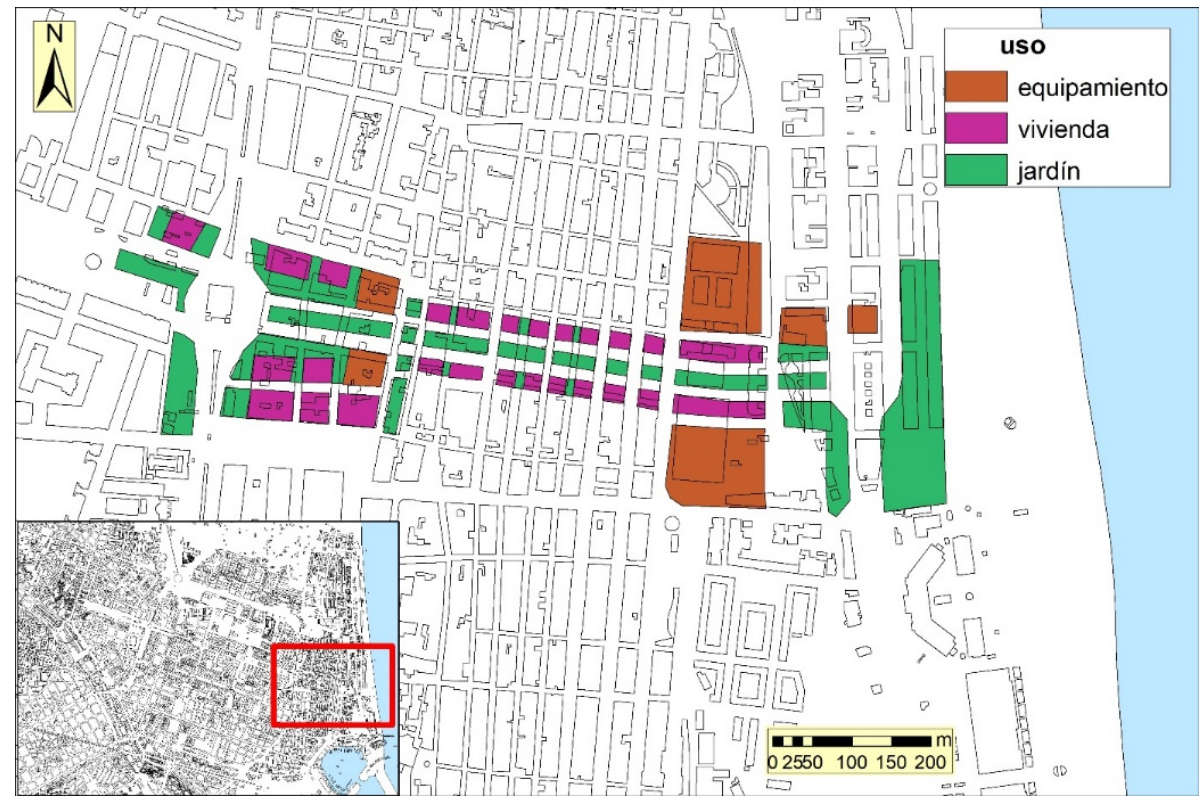

Fuente: elaboración propia a partir de Roger (2019)

\subsection{Brecha trinchera}

La demolición de la muralla del siglo XIV de València liberó un espacio que, a manera de brecha trinchera, fue ocupado por la ronda Interior que, a la postre, influyó en la futura disposición radioconcéntrica de la ciudad, formada por una segunda ronda (Exterior), una tercera (Trànsits), y una cuarta (Periférica) (Figura 8). 
Figura 8. València: esquema radioconcéntrico y Jardín del Turia

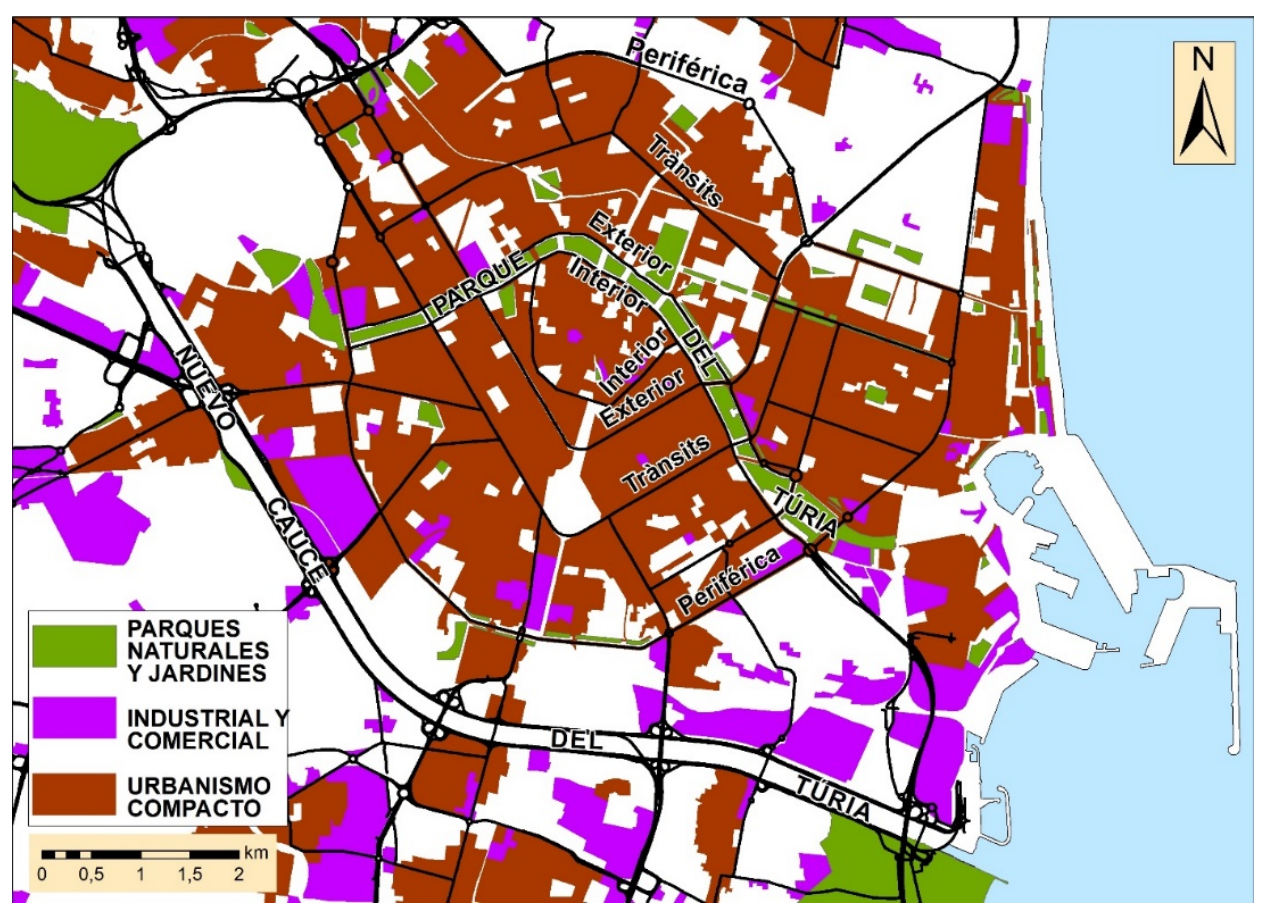

Fuente: elaboración propia. Base cartográfica: SIOSE 2006 (ICV, 2020d)

\subsection{Brecha orográfica}

Entre las barreras físicas que han alterado la trama viaria de València cabe destacar el río Turia. Por un lado, frenó el crecimiento urbano al norte del río, ya que solo con la Exposición Regional de 1909 se empezó la urbanización decidida al otro lado del Turia. Por otro, tanto la margen derecha como la izquierda del río han creado sendas brechas orográficas que han guiado el crecimiento transversal de oeste a este.

Debido a la catastrófica riada de 1957, se planificó el desvío del río por fuera de la ciudad (Plan Sur, 1972), y en 1986 se abrió el primer tramo del jardín del Turia, que ocupa las 200 hectáreas de espacio liberado dentro del cauce del río (parte de ellas frente a la misma Ciutat Vella). En la actualidad este parque longitudinal, que mide $8 \mathrm{~km}$ de oeste a este y $200 \mathrm{~m}$ de norte a sur, supone la mayor brecha viaria en toda la ciudad (Figura 9).

Aparte del curso fluvial del Turia, hay paleocauces fluviales, completamente secos, que también condicionaron la trama viaria de València. Estos solo son reconocibles porque se encuentran en una cota más baja. Se trata de las vaguadas del Mercat y de Les Barques, que eran las zonas más expuestas a las riadas y que conforman una brecha orográfica en su recorrido (Figura 9). 


\section{Figura 9. Brechas orográficas en la Ciutat Vella de València}

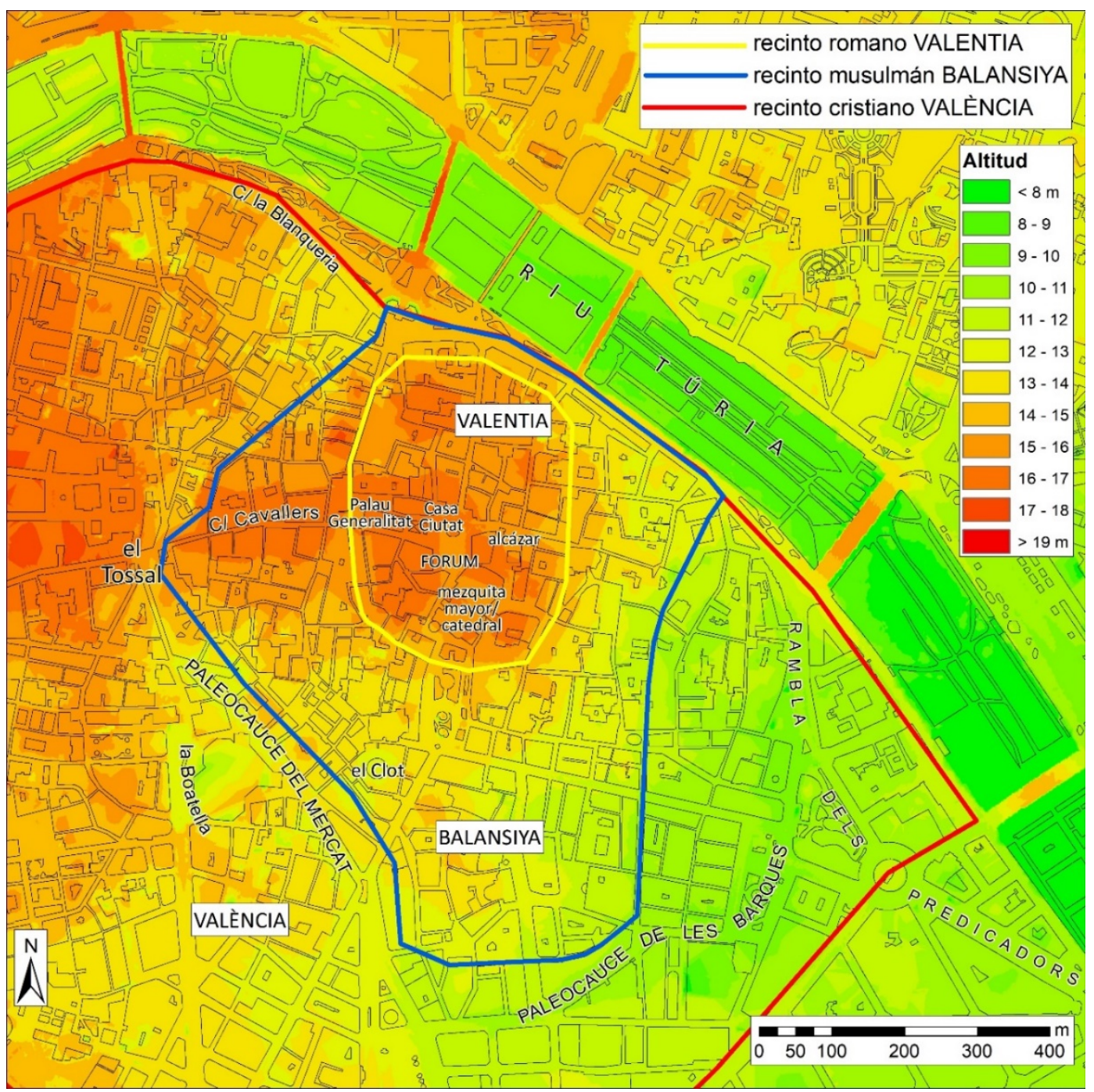

Fuente: elaboración propia a partir de Membrado-Tena (2016, p. 38) y LIDAR (ICV, 2020b)

Por otro lado, hay que señalar que la ciudad romana ocupa una cota más alta. Desde esta las calles descienden en todas direcciones, salvo hacia el oeste, donde la cota es también alta. En momentos de inundación tanto la ciudad romana como las calles al oeste de esta quedaban a salvo, y, por ello, en época medieval, la ciudad romana fue ocupada por las autoridades eclesiásticas (catedral) y políticas (Palau de la Generalitat, Casa de la Ciutat) y las calles al oeste de esta por la clase nobiliaria (calle dels Cavallers) (Membrado-Tena, 2017, p. 383) (Figura 9). Las zonas circundantes, expuestas a las riadas, en cambio, fueron ocupadas mayormente por clases menestrales, comerciantes y minorías étnico-religiosas (Judería, Morería), que no se podían costear una vivienda en la zona alta. El palimpsesto viario, por tanto, no solo se relaciona con elementos tangibles como el desnivel del terreno, sino también con factores de carácter intangible, como la distribución de las clases sociales en función del propio desnivel urbano. 


\subsection{Brecha cubierta y brecha fósil}

La revolución industrial introdujo el ferrocarril, que transportaba mercancías y personas a velocidades notables. Con la demolición de las murallas, los caminos de hierro pronto se convirtieron en el gran obstáculo para el crecimiento urbano, y generaron nuevas brechas viarias.

Figura 10. Ferrocarriles y tranvías históricos en la ciudad de València (c. 1950)

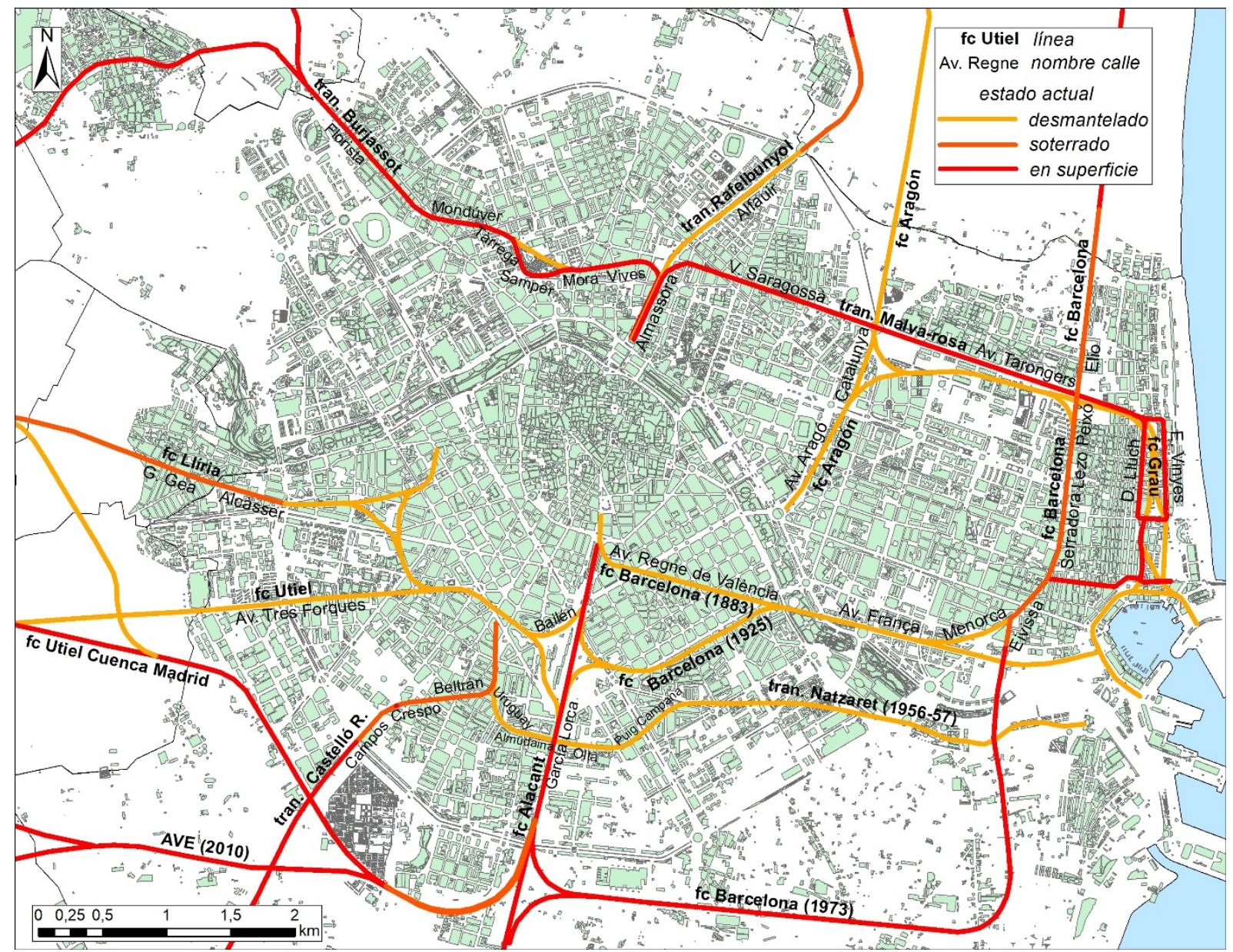

Fuente: elaboración propia a partir de Llopis \& Perdigón (2016) (Plano de Valencia y sus alrededores, 1882; Plano general de Valencia, 1925) e ICV (2020a)

A mediados del siglo XX la ciudad de València estaba rodeada de un cinturón de hierro que ha impreso sobre su trama viaria brechas de tipo fósil (por desmantelamiento), cubierta (por soterramiento) o barrera (donde perduran las vías férreas) (Figura 10). Las calles del Marqués de Sotelo, Regne de València, França y Menorca vienen definidas por las antiguas vías del ferrocarril de València-Tarragona (1868), que perduraron hasta la inauguración de la nueva estación del Nord en 1917. Entonces el tendido de la vía férrea que iba a Barcelona se desplazó 
hacia el sur, paralelo a la ronda de Trànsits (Peris y Valero). Con la inauguración del nuevo cauce (1972), se desmantelaron de nuevo las vías, que fueron llevadas dos kilómetros más al sur, por donde circulan en la actualidad. La entrada del tren de Barcelona se efectuaba a cielo abierto por el límite oeste de la Malva-rosa y el Cabanyal-Canyamelar, hasta que el tendido ferroviario se soterró en 1991. Su huella, a través de una brecha cubierta, es hoy presente en la calle Serradora (Serrería) y su continuación hacia el norte (L. Peixó, F. Elio) y el sur (Eivissa).

\subsection{Brecha costura}

A escala general, el crecimiento urbano del último siglo ha producido brechas costura, que separan los cascos antiguos de los ensanches burgueses y estos de las expansiones funcionalistas. En la ciudad de València se aprecian notablemente estas costuras entre el ensanche burgués de principios del siglo XX y los bloques funcionalistas de la segunda mitad del siglo XX. La ronda de Trànsits, en general, marca dichas discontinuidades (ver Figuras 8 y 16).

\subsection{Brecha barrera}

La trama urbana del municipio de València carece de urbanismo expansivo, pero no su corona metropolitana. Núcleos como Godella, Rocafort, Bétera, I'Eliana, la Canyada (Paterna) o Ribaroja, al noroeste, o el Vedat (Torrent) y Calicanto (Chiva), al suroeste, concentran este tipo de edificación extensiva, que está aislado de los centros urbanos compactos por una o varias autopistas que actúan como brecha barrera (Figura 11).

Asimismo, a pesar de haber sido desmantelado o soterrado en gran parte, el ferrocarril todavía marca una notable brecha barrera dentro del casco urbano de València, al sur de la ciudad (ver Figuras 10 y 16). 
Figura 11. Zona de Urbanismo Expansivo al oeste de la Corona Metropolitana de València

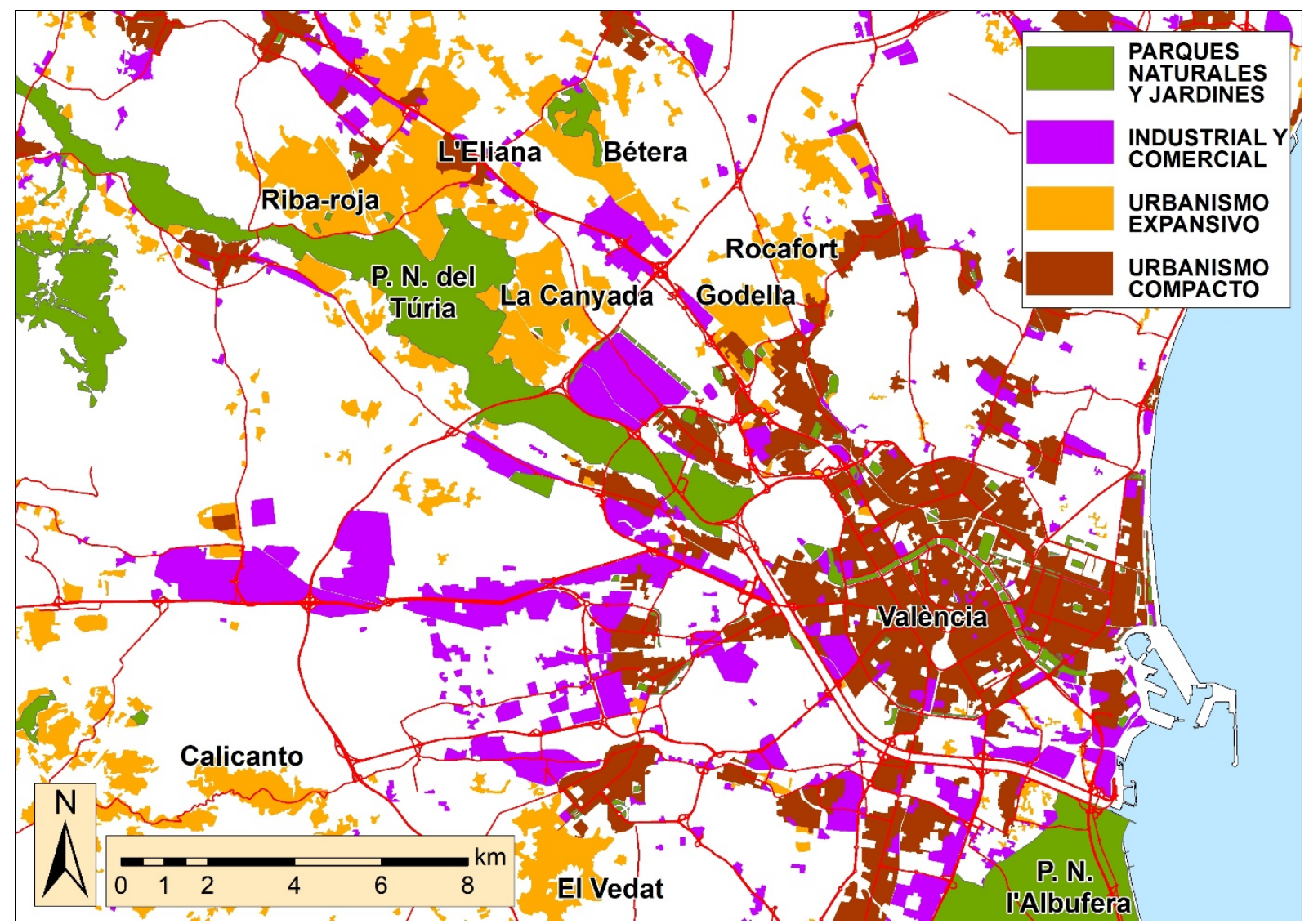

Fuente: elaboración propia a partir de SIOSE 2006 (ICV, 2020d)

\subsection{Resumen}

Como resumen de resultados, se muestra a continuación una breve descripción escrita y gráfica (Figuras 12, 13, 14, 15 y 16) de cada tipo de brecha definido, así como una síntesis de las mismas (Tabla 1). Las figuras se corresponden a ejemplos de la ciudad de València.

La brecha directa es la que más se acerca a la definición de la RAE del vocablo brecha, que es la de "rotura o abertura irregular" y corresponde normalmente a un camino histórico de traza irregular que se yuxtapone transversalmente a una trama urbana (Figura 12).

La brecha inversa es lo contrario de la directa, ya que corresponde a un eje viario regular y planificado que cruza transversalmente una trama urbana; a veces, la brecha inversa es resultado del destripamiento (sventramento en italiano) de una trama anterior (Figura 13). 
Figura 12. Brecha directa (ejemplos de la ciudad de València)

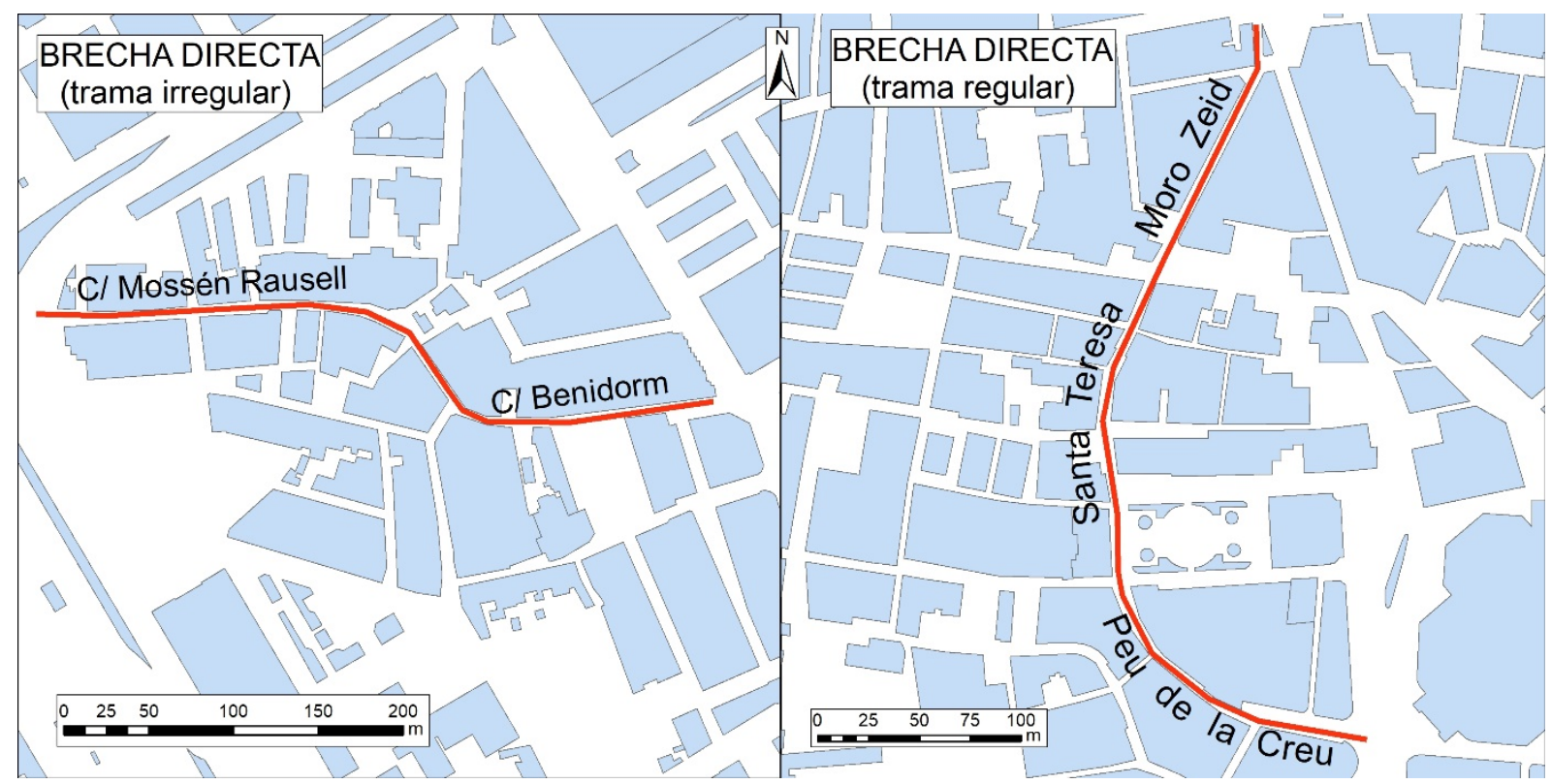

Fuente: elaboración propia. Base cartográfica: CNIG (2020)

Figura 13. Brecha inversa (ejemplos de la ciudad de València)

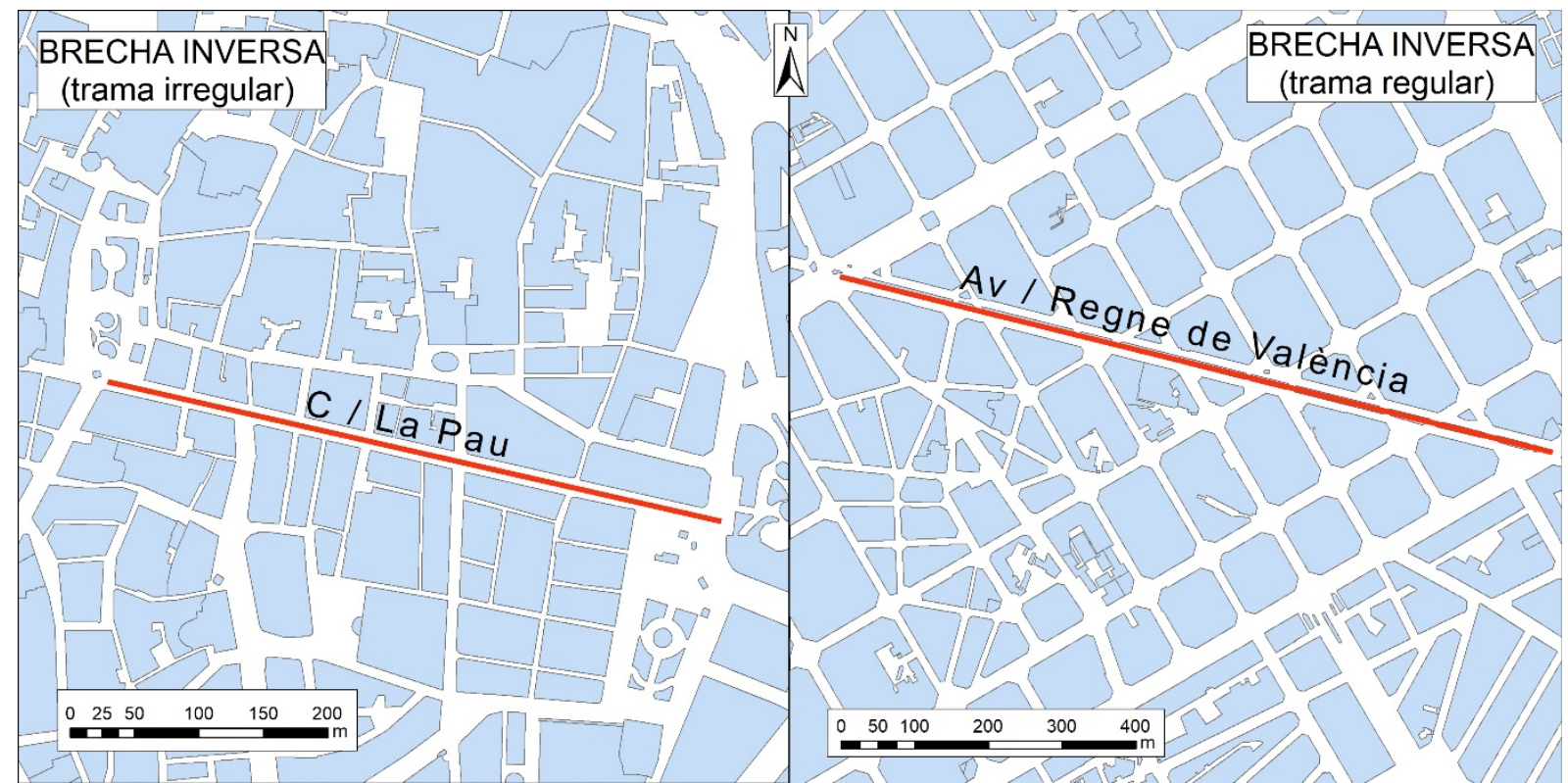

Fuente: elaboración propia. Base cartográfica: CNIG (2020)

Si en lugar de destruir la trama histórica se acomoda a la misma al ocupar el lugar dejado por las murallas se trataría de una brecha trinchera (Figura 14). La trinchera podría ocupar el espacio dejado por otros edificios (no necesariamente las murallas), como en el caso de la Rambla del Raval (Barcelona) (ver Figura 1). 
Cuando la calle se adapta a la forma del relieve (sea por una depresión o por una elevación), se trata de una brecha orográfica (Figura 14).

Figura 14. Brecha trinchera y brecha orográfica (ejemplos de la ciudad de València)

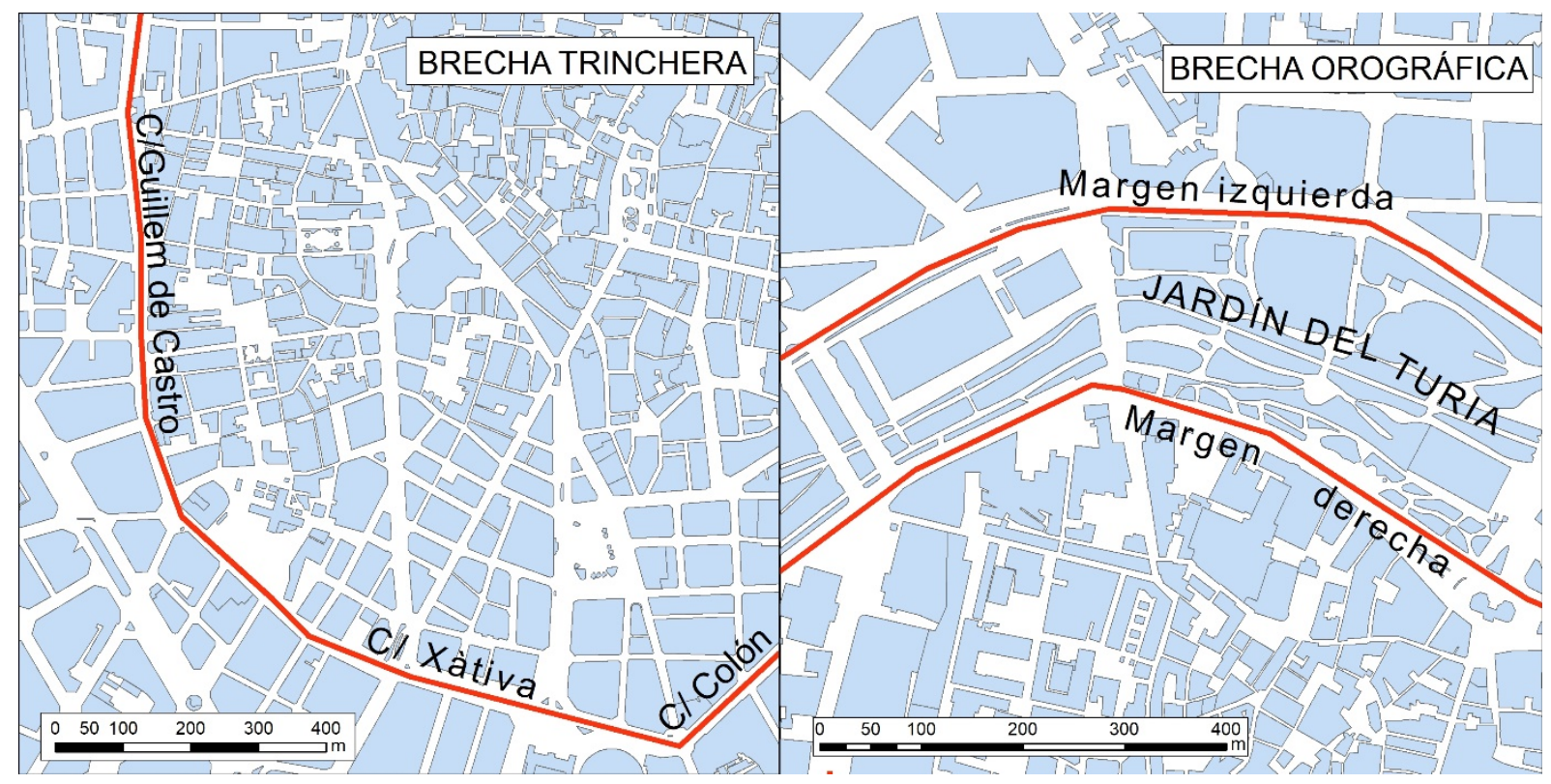

Fuente: elaboración propia. Base cartográfica: CNIG (2020)

Figura 15. Brecha cubierta y brecha fósil (ejemplos de la ciudad de València)

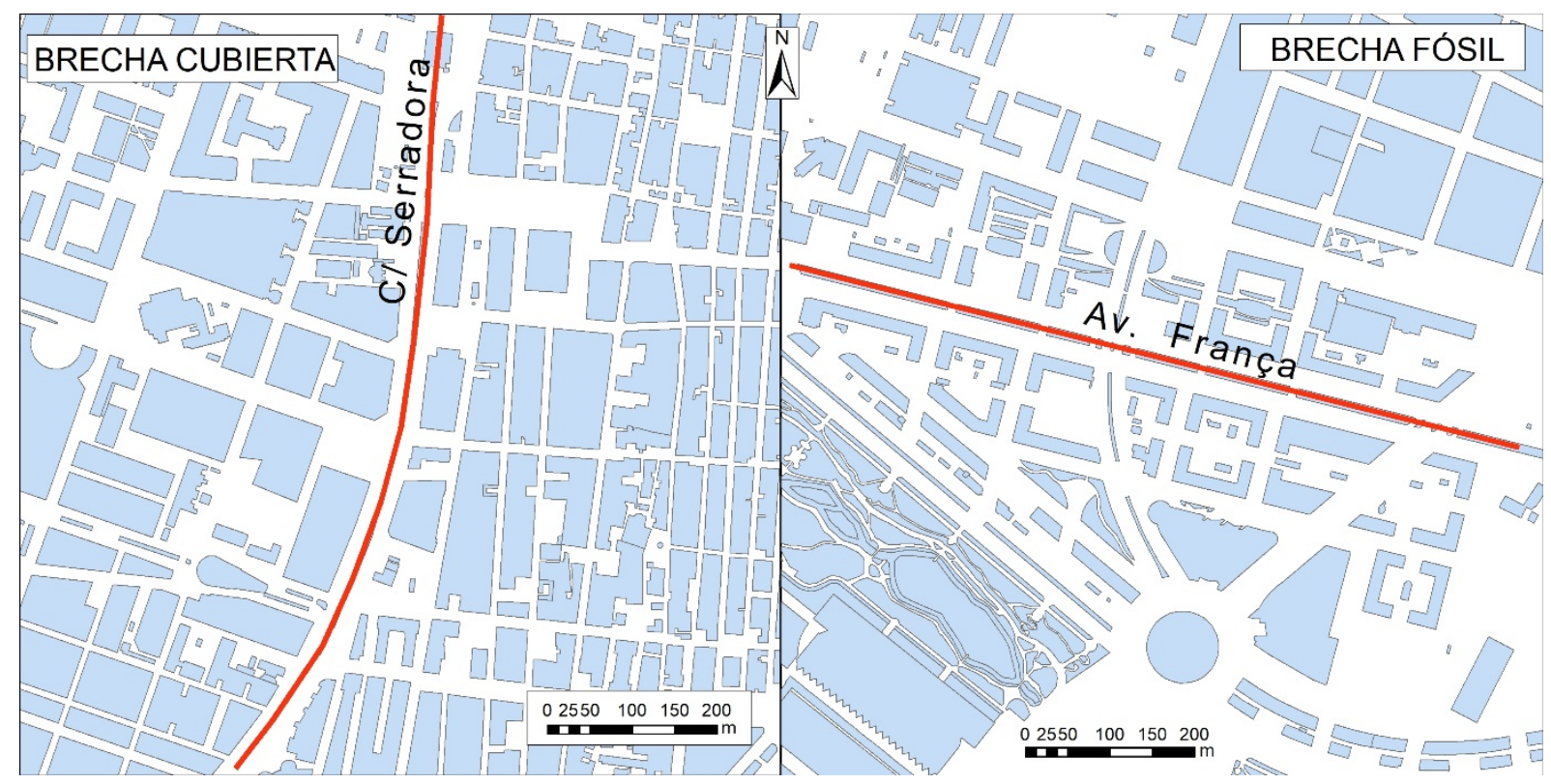

Fuente: elaboración propia. Base cartográfica: CNIG (2020) 
Figura 16. Brecha costura y brecha barrera (ejemplos de la ciudad de València)

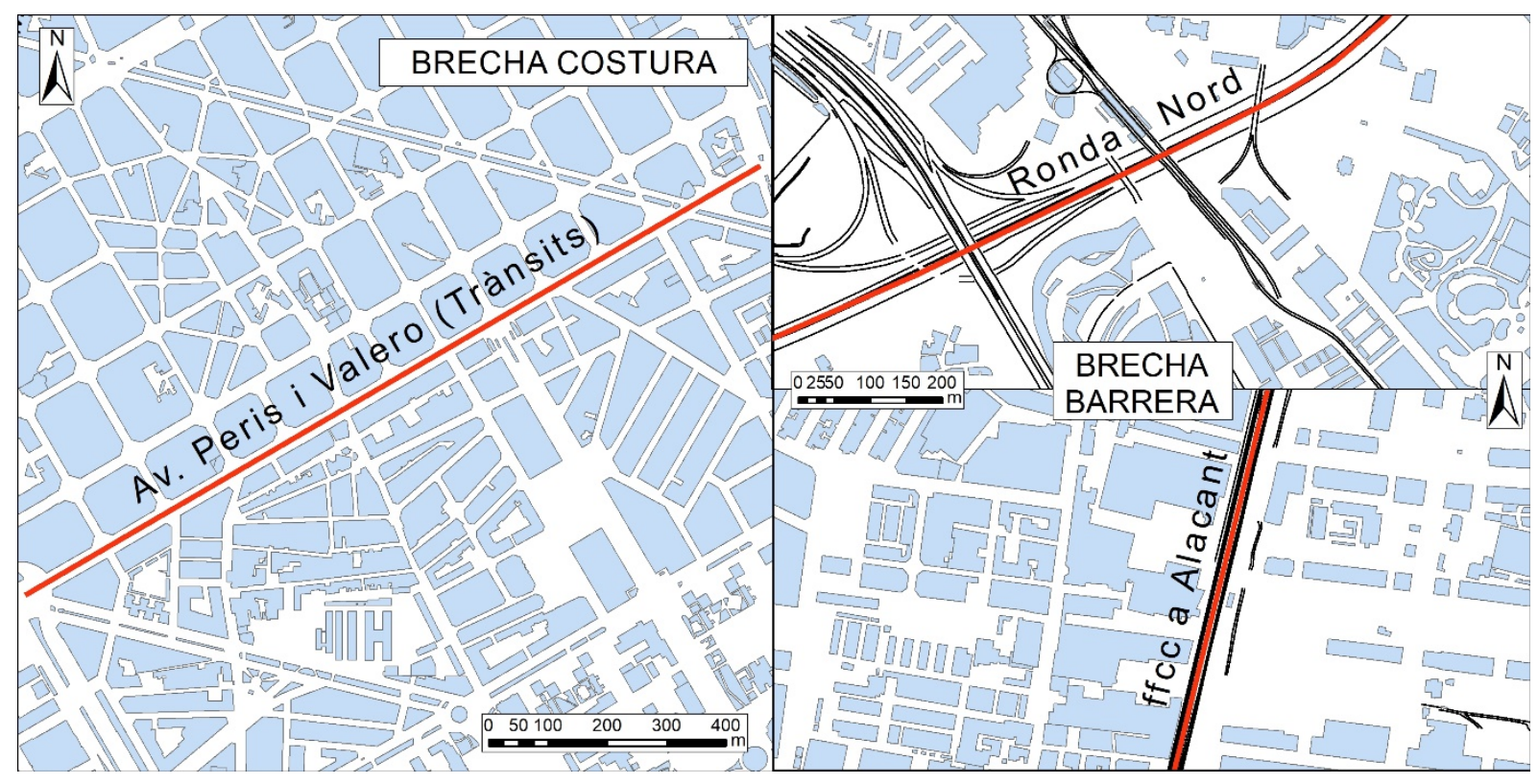

Fuente: elaboración propia. Base cartográfica: CNIG (2020)

Tabla 1. Tipología de brecha viarias

\begin{tabular}{|l|l|l|}
\hline \multicolumn{1}{|c|}{ Brecha } & \multicolumn{1}{|c|}{ Origen } & \multicolumn{1}{c|}{ Forma } \\
\hline Directa & $\begin{array}{l}\text { Espontáneo (camino, } \\
\text { canal) }\end{array}$ & $\begin{array}{l}\text { transita transversalmente sobre trama } \\
\text { planificada o espontánea }\end{array}$ \\
\hline Inversa & Planificado (calle) & $\begin{array}{l}\text { transita transversalmente sobre trama } \\
\text { espontánea o planificada }\end{array}$ \\
\hline Trinchera & $\begin{array}{l}\text { Espontáneo (calle y } \\
\text { edificios) }\end{array}$ & ocupa el espacio de una edificación demolida \\
\hline Orográfica & $\begin{array}{l}\text { Espontáneo (calle o } \\
\text { camino) }\end{array}$ & se adapta la forma del relieve \\
\hline Cubierta & $\begin{array}{l}\text { Planificado (calle, vía } \\
\text { férrea, metro, canal) }\end{array}$ & cubre una infraestructura viaria en uso \\
\hline Fósil & $\begin{array}{l}\text { Planificado (calle y vía } \\
\text { férrea) }\end{array}$ & $\begin{array}{l}\text { ocupa el espacio de una infraestructura viaria } \\
\text { desmantelada }\end{array}$ \\
\hline Costura & Planificado (calle) & separa dos tramas viarias distintas \\
\hline Barrera & $\begin{array}{l}\text { Planificado (vía férrea, } \\
\text { autopista) }\end{array}$ & separa físicamente dos sectores urbanos \\
\hline
\end{tabular}

Fuente: elaboración propia

La brecha cubierta describe una calle o avenida bajo la cual circula soterrada una infraestructura (ferrocarril, metro, calle, canal) (Figura 15). La brecha fósil se refiere a una calle o avenida por la que previamente hubo una infraestructura que luego fue desmantelada (Figura 15). 
La brecha costura describe una calle o avenida planificada que cose dos tramas urbanas distintas, entre las que hay una notable interrupción viaria (Figura 16). Cuando la brecha impide la comunicación peatonal se trata de una brecha barrera (Figura 16).

\section{Discusión}

En el capítulo de resultados se ha definido una clasificación de brechas viarias, a través de una profunda interpretación del palimpsesto mediante técnicas cartográficas, donde se ha primado la perspectiva descriptiva propia de la Ecología del paisaje, frente a otros enfoques paisajísticos de carácter intangible y perceptivo. Muchos autores (Engbersen, 2001; Huyssen, 2003; Samuelson, 2008; Marvell \& Simm, 2016; Hartwiger, 2016) vinculan el palimpsesto a la percepción de los espacios urbanos, mientras que otros (Corboz, 2004; Vâlceanu et al., 2014) reflexionan sobre el valor patrimonial del palimpsesto urbano y la necesidad de su preservación, y alguna, como Nadia Bartolini (2014), llega a teorizar sobre el contenido semántico de este término y llega a proponer la definición de brecha para la yuxtaposición de elementos del pasado, frente a la de palimpsesto para la superposición de los mismos. Aunque esta matización terminológica es interesante, en este artículo se ha respetado la definición integral y metafórica de palimpsesto urbano como trama viaria derivada de una estructura histórica que se refleja en trazados incoherentes (Crang, 1996; Oliveira, 2016; y Fouseki et al., 2019). La complejidad del palimpsesto supera la mera distinción entre brechas superpuestas y yuxtapuestas, ya que estas pueden ser, además, directas o inversas, espontáneas o planificadas, históricas o contemporáneas, originales (creadas sobre un espacio agrícola o forestal) o recicladas (creadas sobre un espacio urbano liberado).

Nuestra taxonomía de brechas se resume en ocho tipos (Tabla 1). Cabe señalar que algunos de los ejemplos pueden responder a más de uno de los tipos propuestos (en cuyo caso lo hemos adscrito al tipo más significativo). Se trata de una categorización jerárquica basada, en primer lugar, en la estructura formal, y en segundo, en su origen funcional. Estructura y funcionamiento son dos conceptos relacionados que explican la dinámica del paisaje y que, a la vez, son una de las bases de la Ecología del paisaje (Antrop, 2000, p. 19).

Por lo que respecta a las técnicas cartográficas, algunas autoras han trabajado los palimpsestos del paisaje natural o cultural aplicados a su caso de estudio (Khirfan, 2010; Klimanova \& Kolbowsky, 2017; Johnson \& Ouimet, 2018), pero sin llegar a crear una tipología de brechas urbanas extrapolable a otros casos de estudio. 
Para llevar a cabo nuestro objetivo los Sistemas de Información Geográfica han resultado muy convenientes, ya que una de sus aplicaciones más potentes es precisamente la superposición de capas cartográficas para llegar a cabo análisis territoriales complejos. Y en eso consiste un palimpsesto: en una superposición y yuxtaposición de etapas históricas que pueden ser desencriptadas mediante ciertas técnicas, igual que la complejidad evolutiva del plano urbano puede ser analizada si se dispone de información cartográfica relevante y de un software adecuado.

Por último, las teorías y modelos descritos en el apartado 2 por Grant (2001), Capel (2002), Mumford (2002), Gillham (2002), García-Doménech et al (2012), Gomis \& Turón (2015) o Álvarez et al. (2016) se ajustan, en general, a la secular evolución urbana de València. Dada su antigüedad (acaba de cumplir 2158 años), València posee tal complejidad urbana que puede considerarse una ciudad paradigma para esta investigación, de manera que la tipología de brechas viarias creada puede ser fácilmente extrapolable a otros casos complejos de estudio, si se aplica la misma metodología con los materiales apropiados.

\section{Conclusión}

El objetivo principal y aportación más novedosa de este artículo ha sido la creación, mediante una metodología específica creada por los autores y una serie de material planimétrico y cartográfico, de una tipología de brechas viarias (directa, inversa, trinchera, orográfica, cubierta, fósil, costura o barrera), basadas en su estructura y funcionamiento. Dicha categorización, como se acaba de explicar en la discusión de resultados, aunque se ha implementado para el caso de la ciudad de València, es extrapolable a cualquier ámbito urbano complejo si se aplica la metodología expuesta con el material adecuado.

Los distintos tipos de huellas viarias que se generan - por superposición o yuxtaposición de trazados- a lo largo de una secular evolución urbana suponen una anomalía dentro de un tejido más o menos coherente que otorga singularidad y carácter al paisaje urbano y lo convierte en un palimpsesto. Estas brechas viarias -transversales, sinuosas u oblicuas- no solo constituyen una valiosa herencia patrimonial, sino que además poseen un enorme valor identitario para sus residentes.

De hecho, el auge de los valores patrimoniales e identitarios durante las últimas décadas se ha traducido en un creciente interés de las ciudades por la preservación de su trama histórica edilicia y viaria. Sin salir del ámbito de nuestro caso de estudio, cabe señalar algunas iniciativas 
que está llevando a cabo el ayuntamiento de València para la conservación integral de las alineaciones históricas de la trama urbana de su centro histórico (Elperiodic.com, 2017; Noticiasde, 2020). Otro de los objetivos de este artículo era, precisamente, que su contenido se convirtiera en una herramienta de apoyo documental y gráfico para sustentar dichas iniciativas municipales que, más allá de la conservación de la trama edilicia, pretenden también la preservación de la trama viaria. Se trata, por tanto, de que este documento se convierta en un instrumento de aplicación social y transferencia de conocimientos al entorno de la planificación urbanística, en general, y de la preservación de centros históricos, en particular. Además, la metodología y resultados de este trabajo, en tanto que extrapolables a otros ámbitos urbanos, permitirían su aplicación a cualquier otro ámbito urbano donde, como en el caso de València, la conservación de las brechas viarias, y de la trama urbana en su conjunto, sea objeto de políticas activas.

Declaración responsable: Las/os autoras/es declaran que no existe ningún conflicto de interés con relación a la publicación de este artículo. Las tareas se han distribuido de la siguiente manera: el artículo ha sido coordinado por J. C. Membrado, que ha llevado a cabo también la revisión bibliográfica. Los tres autores (J. C. Membrado, J. Hermosilla y G. Fansa) han participado en la redacción y discusión del artículo. La elaboración de mapas estuvo a cargo de J. C. Membrado y G. Fansa. 


\section{Bibliografía}

Aguilar, I., \& Serra, A. (2017). Los Poblados Marítimos. Historia, lugares y escenas. València: Ajuntament.

Alisio, G. (1980). Napoli e il risanamento. Nápoles: Edizioni scientifiche italiane.

Álvarez, E. J., Hernández, M., \& Tort, A. (2016). Modelo morfológico de crecimiento urbano inducido por la infraestructura ferroviaria. Estudio de caso en 25 ciudades catalanas. Scripta Nova, 20 (527). https://doi.org/10.1344/sn2016.20.15789

Antrop, M. (2000). Background concepts for integrated landscape analysis. Agriculture, ecosystems \& environment, 77(1-2), 17-28. https://doi.org/10.1016/S0167-8809(99)00089-4

Bartolini, N. (2014). Critical urban heritage: From palimpsest to brecciation. International Journal of Heritage Studies, 20(5), 519-533. https://doi.org/10.1080/13527258.2013.794855

Bielza de Ory, V. (2002). De la ciudad ortogonal aragonesa a la cuadrícula hispanoamericana como proceso de innovación-difusión, condicionado por la utopía. Scripta Nova, 6(105-132). Retrieved from http://revistes.ub.edu/index.php/ScriptaNova/article/view/439

Boira, J. V. (2001). El carrer de la Pau. In Rosselló, V. M. (Ed.), La Universitat i el seu entorn urbà (pp. 147-170). València: Universitat de València.

Boira, J.V. (2019). Los límites del cambio en la política urbana: ciclo electoral y herencia recibida en el barrio del Cabanyal-Canyamelar (València). In R. C. Lois \& O. Rullan (Coord.), Planificando desde la geografía profesional (pp.117-132). Universidade de Santiago de Compostela.

Boira, J. V. (2020). Roma i nosaltres. Barcelona: Pòrtic.

Bonillo, J. L., \& Borruey, R. (1992). Marseille, ville \& port. Marsella: Parenthèses.

BVM (2020). Plano de Madrid de 1866 de José Pilar Morales. Biblioteca Virtual de Madrid. Retrieved from

http://bibliotecavirtualmadrid.org/bvmadrid_publicacion/i18n/consulta/registro.do?id=55

Calci, C. (2012). La via Flaminia ai Due Ponti. Roma: Municipio di Roma XX.

Capel, H. (1999). El Rec Comtal y otros canales mediterráneos. Biblio 3w, 4(157). Retrieved from http://www.ub.edu/geocrit/b3w-157.htm

Capel, H. (2002). La morfología de las ciudades. Tomo I: Sociedad, cultura y paisaje urbano. Barcelona: Ediciones del Serbal. 
Carmona, P. (1997). La dinámica fluvial del Turia en la construcción de la ciudad de Valencia. Documents d'Anàlisi Geogràfica, 31, Retrieved from https://ddd.uab.cat/record/1206

Cho, H. C. (2011). Venice and Its Location. Hartford: Trinity College. Retrieved from http://digitalrepository.trincoll.edu/fypapers/25

CNIG (2020). Base Topográfica Nacional 1:25.000 (BTN25). Centro Nacional de Información Geográfica. Madrid: Ministerio de Transporte, Movilidad y Agenda Urbana.

Corboz, A. (2004). El territorio como palimpsesto. In Lo urbano en 20 autores contemporáneos (pp. 25-34). Barcelona: Universitat Politècnica de Catalunya.

Crang, M. (1996). Envisioning urban histories: Bristol as palimpsest, postcards, and snapshots. Environment and Planning A, 28(3), 429-452. https://doi.org/10.1068/a280429

De Moncan, P., \& Heurteux, C. (2002). Le Paris d'Haussmann. Paris: Mécène.

Dillon, S. (2005). Reinscribing De Quincey's palimpsest: The significance of the palimpsest in contemporary literary and cultural studies. Textual Practice, 19(3), 243263. https://doi.org/10.1080/09502360500196227

Elperiodic.com (2017, October 27). El Plan especial de protección de Ciutat Vella recuperará la trama urbana histórica. Elperiodic.com. Retrieved from https://www.elperiodic.com/valencia/plan-especial-proteccion-ciutat-vella-recuperaratrama-urbana-historica_531158

Engbersen, G. (2001). The urban palimpsest. Focaal-European Journal of Anthropology, (38), $125-138$.

Esquilache, F. (2015). Els espais agraris i l'estructura social d'una gran horta fluvial andalusina. Tesis doctoral : Universitat de València.

Feroci, S., \& Vibrac, D. (2018). Une promenade à Paris avec Giacomo Casanova. Fiesole: Edizioni Fiesolane.

Fouseki, K., Guttormsen, T. S., \& Swensen, G. (2019). Heritage and Sustainable Urban Transformations: Deep Cities. London: Routledge.

Francesio, G., Russo, E., \& Minnella, M. (2012). Sicilia: storia e arte. Verona: Arsenale editrice. 
García-Doménech, S., Ros, D., \& Martí, P. (2012). La expresión gráfica en los proyectos de ordenación urbana. Antecedentes históricos y una apuesta de normalización. EGA, 17(20), 202-213. https://doi.org/10.4995/ega.2012.1442

Gillham, O. (2002). The Limitless City: a Primer on the Urban Sprawl Debate. Washington DC: Island Press.

Gomis, J., \& Turón, C. (2015). Conceptual and instrumental influences in the graphic representation of urban planning: the industrial revolution and the 19th century. Geographia Technica, 10(1), 44-50. Retrieved from

http://www.technicalgeography.org/pdf/1_2015/05_gomis.pdf

Grant, J. (2001). The dark side of the grid: power and urban design. Planning Perspectives, 16(3), 219-241. https://doi.org/10.1080/02665430152469575

Hartwiger, A. G. (2016). The Postcolonial Flâneur: Open City and the Urban Palimpsest. Postcolonial Text, 17(1).

Hebbert, M. (2018). The long after-life of Christopher Wren's short-lived London plan of 1666. Planning Perspectives, 1-22. https://doi.org/10.1080/02665433.2018.1552837

Hermosilla Pla, J., \& Iranzo, E. (2014). Claves geográficas para la interpretación del patrimonio hidráulico mediterráneo. A propósito de los regadíos históricos valencianos. Boletín de la Asociación de Geógrafos Españoles, 66, 49-66. https://doi.org/10.21138/bage.1779

Hervás, J. (2017). El barrio del Cabanyal-Canyameral de Valencia: historia y futuro. Ciudad y territorio: Estudios territoriales, 191, 81-97. Retrieved from https://recyt.fecyt.es/index.php/CyTET/article/viewFile/76528/46866

Higgins (2009). The grid book. Cambridge, MA: MIT Press.

Huyssen, A. (2003). Present pasts: Urban palimpsests and the politics of memory. Palo Alto: Stanford University Press.

ICGC (2020). Plano de Barcelona con la división de distritos. Sistema Acklin. 1855. Institut Cartogràfic i Geològic de Catalunya. Retrieved from http://cartotecadigital.icc.cat/cdm/ref/collection/catalunya/id/1756

ICV (2020a). Vuelo americano 1956-1957 de la Comunitat Valenciana. València: Institut Cartogràfic Valencià. 
ICV (2020b). LIDAR-PNOA de 2009 de la Comunitat Valenciana. València: Institut Cartogràfic Valencià.

ICV (2020c). Ortofotografía de 2019 de la Comunitat Valenciana. València: Institut Cartogràfic Valencià.

ICV (2020d). Sistema de Información sobre Ocupación del Suelo de España (SIOSE) de 2006 de la Comunitat Valenciana. València: Institut Cartogràfic Valencià.

Jankowski, S. (1990). Warsaw: destruction, secret town planning, 1939-44, and postwar reconstruction. In Rebuilding Europe's bombed cities (pp. 77-93). London: Palgrave Macmillan.

Johnson, K. M., \& Ouimet, W. B. (2018). An observational and theoretical framework for interpreting the landscape palimpsest through airborne LiDAR. Applied Geography, 91, 32-44.

Khirfan, L. (2010). Traces on the palimpsest: Heritage and the urban forms of Athens and Alexandria. Cities, 27(5), 315-325. https://doi.org/10.1016/j.cities.2010.03.009

Klimanova, O., \& Kolbowsky, E. Y. (2017). Types of Cultural Palimpsest Landscapes in the Mediterranean Basin: Delimitation and Mapping. European Journal of Geography, 8(3), $78-91$.

Legorreta, J. (2006). El agua y la Ciudad de México: de Tenochtitlán a la megalópolis del siglo XXI. México D.F.: Universidad Autónoma Metropolitana.

Lima, M. C., \& Neto, M. J. B. (2017). Duas catástrofes históricas: o Grande Incêndio de Londres e o Terramoto de Lisboa de 1755-efeitos no Património Artístico e atitudes de recuperação. Conservar património, 25, 37-41.

Llopis, A. \& Perdigón, L. A. (2016). Cartografía histórica de la ciudad de Valencia (16081944). València: Universitat Politècnica de València.

Mantecón, A., Membrado-Tena, J. C., \& Huete, R. (2016). Fragmentación socio-espacial, inmigración europea y discursos políticos en la Provincia de Alicante. Boletín de la Asociación de Geógrafos Españoles, 72, 67-90. http://dx.doi.org/10.21138/bage.2332

Martí, J. (2002). A la luna de Valencia. Una aproximación arqueológica al espacio periurbano de la ciudad musulmana. In Ortolá, S. D., Pastor, F. T., \& Taberner, F. (Ed.), Historia de la Ciudad II (pp. 55-73). València: Colegio de Arquitectos.

Marvell, A., \& Simm, D. (2016). Unravelling the geographical palimpsest through fieldwork: discovering a sense of place. Geography, 101(3), 125-136. 
Mazower, M. (2007). Salonica, city of ghosts: Christians, Muslims and Jews 1430-1950. Taylorsville, NC: Vintage.

Membrado-Tena, J. C. (2015). Migración residencial y urbanismo expansivo en el Mediterráneo español. Cuadernos de Turismo, 35, 259-286. https://doi.org/10.6018/turismo.35.221611

Membrado-Tena, J. C. (2016). Identificación de orotopónimos irrelevantes mediante lidar. GeoFocus, 18, 25-45. http://dx.doi.org/10.21138/GF.463

Membrado-Tena, J. C. (2017). La relación entre toponimia urbana y topografía en la Ciutat Vella de Valencia: análisis mediante métodos cuantitativos y cualitativos. Boletín de la Asociación de Geógrafos Españoles, 74, 361-386. https://doi.org/10.21138/bage.2458

Meyer, M. (2010). The last days of old Beijing: Life in the vanishing backstreets of a city transformed. Nueva York: Bloomsbury.

Mumford, E. P. (2002). The CIAM discourse on urbanism, 1928-1960. Cambridge: MIT Press.

Navarro, J., \& Jiménez, P. (2012). La gestión del agua en la ciudad andalusí: el caso de Murcia. Murcia: Fundación Séneca.

Nogué, J. (2007). Territorios sin discurso, paisajes sin imaginario: retos y dilemas. Ería, 73-74, 373-382. http://www.unioviedo.es/reunido/index.php/RCG/article/view/1593/1508

Noticiasde (2020, February 27). La aprobación del plan especial de protección de Ciutat Vella impulsa la recuperación de espacio público y el equilibrio dotacional. Noticiasde. Retrieved from https://www.noticiasde.es/comunidad-valenciana/valencia/la-aprobacion-del-planespecial-de-proteccion-de-ciutat-vella-impulsa-la-recuperacion-de-espacio-publico-y-el-equilibriodotacional/

Oliveira, V. (2016): Urban Morphology: An Introduction to the Study of the Physical Form of Cities. Berlin: Springer.

Orefice, G. (1992). Da Ponte Vecchio a Santa Croce. Piani di risanamento a Firenze. Firenze : Alinea.

Paccoud, A. (2016). Planning law, power, and practice: Haussmann in Paris (1853-1870). Planning Perspectives, 31(3), 341-361. https://doi.org/10.1080/02665433.2015.1089414

Regina, V., \& Giglio, R. (2016). Napoli antica. Roma: Newton Compton.

Roger, G. (2019): El Plan Especial del Cabanyal. Planur-e, verano 2019, miscelánea. Retrieved from https://www.planur-e.es/miscelanea/view/el-plan-especial-del-cabanyal 
Rosselló, V. M. (2018). Viles planificades valencianes medievals i modernes. València: Universitat de València e Institut d'Estudis Catalans.

Samuelson, M. (2008). The urban palimpsest: Re-presenting Sophiatown. Journal of postcolonial writing, 44(1), 63-75.

Sanchis, C. (2002). Acequias, saneamiento y trazados urbanos en Valencia. In S. D. Ortolá, F. T. Pastor \& F. Taberner (Ed.), Historia de la Ciudad II (pp. 92-105). València: Colegio de Arquitectos.

Shackley, M. (1998). Visitors to the world's oldest cities-Aleppo and Damascus (Syria). In D. Tyler, Y. Guerrier \& M. Robertson (Ed.), Managing tourism in cities: policy, process, and practice. Hoboken, NJ: John Wiley \& Sons.

Shengfang, Y. (1986). Waterway System in Suzhou. Architectural Journal, 9.

Semi, G. (2004). II quartiere che (si) distingue. Un caso di" gentrification" a Torino. Studi culturali, 1(1), 83-108.

Teixidor, M. J. (2001). L'entorn geogràfic del barri. In Rosselló, V. M. (Ed.), La Universitat i el seu entorn urbà (pp. 13-42). València: Universitat de València.

Tesser, Claudio (2000). Algunas reflexiones sobre los significados del paisaje para la Geografía. Revista de Geografía Norte Grande, 27, 19-2. Retrieved from https://repositorio.uc.cl/bitstream/handle/11534/10431/000313714.pdf?sequence=1 Vâlceanu, D. G., Kosa, R. A., \& Tamîrjan, D. G. (2014). Urban landscape as palimpsest. Urbanism. Arhitectură. Construcţii, 4, 17-26. Retrieved from https://www.ceeol.com/search/article-detail?id=603613

Wildner, K. (2018). El Zócalo de la Ciudad de México. Un acercamiento metodológico a la etnografía de una plaza. Anuario de espacios urbanos, historia, cultura y diseño, 5, 149-170. 